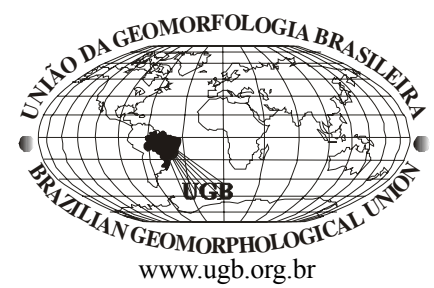

\title{
IDENTIFICAÇÃO DE UNIDADES DE PAISAGEM E SUA IMPLICAÇÃO PARA O ECOTURISMO NO PARQUE NACIONAL DA SERRA DOS ÓRGÃOS, RIO DE JANEIRO
}

\author{
Sandro Nunes de Oliveira \\ Departamento de Geografia da Universidade de Brasília (UnB) \\ sandronunes@unb.br \\ Osmar Abílio de Carvalho Júnior \\ Departamento de Geografia da Universidade de Brasília (UnB) \\ osmarjr@unb.br
}

\author{
Éder de Souza Martins \\ EMBRAPA Cerrados \\ eder@cpac.embrapa.br
}

Telma Mendes da Silva

Instituto de Geociências - Universidade Federal do Rio de Janeiro telmendes@globo.com

Roberto Arnaldo Trancoso Gomes

Departamento de Geografia da Universidade de Brasília (UnB) robertogomes@unb.br

Renato Fontes Guimarães

Departamento de Geografia da Universidade de Brasília (UnB) renatofg@unb.br

\begin{abstract}
Resumo
A análise da heterogeneidade da paisagem é fundamental para o planejamento do ecoturismo porque estima uma relação ótima entre a conservação e as alternativas turísticas. A metodologia de paisagem possibilita descrever não só a beleza cênica, porém também o grau de estabilidade do sistema ecológico. A pesquisa da paisagem para o ecoturismo integra os diferentes componentes naturais (relevo, condições climáticas, solo, cobertura da vegetação, etc.) e avalia suas inter-relações com as características do destino turístico. A geomorfologia é sempre considerada um dos fatores mais importantes que controla a heterogeneidade espacial em áreas com alta variação topográfica. Nesse caso, os parâmetros do relevo indicam a distribuição da temperatura e da umidade, exposição à direção de vento, vegetação, habitat entre outros. A área de estudo é o Parque Nacional da Serra dos Órgãos, um dos mais visitados no Brasil, com um vasto número de opções para visitantes de ecoturismo, tais como diversidade ecológica, significado histórico e oportunidades de recreação. O presente artigo objetiva definir unidades de paisagens do
\end{abstract}


parque nacional da Serra dos Órgãos a partir de sensoriamento remoto e atributos de terreno. Além disso, o artigo analisa a distribuição das atrações turísticas em relação às unidades de paisagem. Assim o procedimento de análise considera os tipos de paisagem, estruturas espaciais e limitações. A metodologia pode ser dividida nos seguintes passos: (a) processamento digital das imagens de atributos de terreno a partir do modelo digital de terreno, (b) interpretação de imagens de sensoriamento remoto, e (c) delimitação e análise das atrações de ecoturismo. A integração dos dados possibilitou identificar unidades em dois diferentes níveis hierárquicos de escala. $\mathrm{Na}$ escala de geossistema, sete classes foram identificadas apresentando diferentes dinâmicas e vulnerabilidades ambientais. O método da análise de paisagem para o ecoturismo permitiu uma perspectiva holística como também uma avaliação do potencial de recreação.

Palavras-chave: Unidades de Paisagem; Modelo Digital de Terreno; Parque Nacional da Serra dos Órgãos; Mata Atlântica; relação solo-vegetação; ecoturismo.

\begin{abstract}
:
Landscape heterogeneity analysis is fundamental in ecotourism planning since it estimates an optimal relationship between conservation and tourist alternatives. The landscape methodology approach enables to describe not only the scenic beauty, but also the degrees of stability in ecological systems. Landscape research for ecotourism integrates the different natural components (relief, climatic conditions, soil, vegetation cover etc.) and evaluates their interrelationships with the characteristics of the tourist destination. The geomorphology is often regarded as one of the most important factors controlling the spatial heterogeneity of the landscape in areas with high topographic variation. In this case, landform parameters indicate temperature and moisture distribution, exposure towards wind, vegetation, habitats etc. The study area is the Serra dos Órgãos National Park, one of Brazil's most visited national parks, with a vast number of options for ecotourism visitors, such as ecological diversity, historical significance and recreational opportunities. The present paper aims to define the landscape units of Serra dos Órgãos National Park from the remote sensing and terrain attributes. Moreover the paper analyzes the distribution of tourist attraction in relation to the landscape units. Thus, the analysis procedure considers the types of landscapes, spatial structures and limitations. The methodology can be divided in the following stages: (a) digital processing of the terrain attributes images from digital elevation model; (b) remote sensing image interpretation, and (c) delimitation and analysis of the ecotourism attraction. The data integration enabled to identify units in two different hierarchical scale levels. In the geosystem scale, seven classes had been identified presenting different dynamics and environmental vulnerabilities. The method of landscape analysis for ecotourism provided a holistic perspective as well as recreational potential evaluation.
\end{abstract}

Keywords: Landscape units; Digital Elevation Model; Serra dos Órgãos National Park; Atlantic Rainforest; soil-vegetation relationship; ecotourism.

\section{Introdução}

Novos paradigmas surgem com a economia global provocando a expansão do setor terciário. Nesta nova configuração, observa-se um aumento do turismo, que se consolida como a terceira maior indústria mundial em termos de produção econômica, perdendo apenas para a indústria petrolífera e a automobilística (Moesch, 2000). Dentro dos ramos do turismo, cada vez mais se consolida o turismo ecológico ou ecoturismo. Assim, a paisagem é um bem natural que se torna cada vez mais consumida devido ao aumento dessa emergente atividade econômica. Diferentemente de outras atividades, o poder de atração econômica e a qualidade do ecoturismo estão vinculados às características de preservação e informações de suas singularidades locais. Desta forma, os agentes do ecoturismo buscam conjugar tanto os fatores sócio-econômicos como os seus valores ambientais e preservacionistas que garantem o aporte de visitação.

O Brasil possui no ecoturismo uma forte alternativa econômica por ser privilegiado em áreas naturais, com ricos patrimônios histórico-culturais. Nessa perspectiva, áreas remotas antes com pouco desenvolvimento podem converterse em áreas propícias para o ecoturismo. Dentre essas áreas, destacam-se as várias Unidades de Conservação (UC's) existentes no país, que são regulamentadas pelo Sistema Nacional de Unidades de Conservação (SNUC) instituído pela Lei $\mathrm{n}^{\circ}$ 9.985, de 18 de julho de 2000, que estabelece critérios e normas para sua criação, implantação e gestão. A exploração do turismo dos parques nacionais pode garantir recursos para ampliar as áreas de proteção e aumentar a eficiência da fiscalização e consciência ecológica pela própria sociedade; que passa a depender da sua conservação para o seu 
desenvolvimento econômico, trazendo benefícios tanto à comunidade como para o meio ambiente.

Para evitar o uso predatório é necessário estabelecer critérios de utilização a partir de documentos que permitam orientar a ocupação das áreas protegidas de forma harmoniosa com sua vocação natural. Dentro dessa perspectiva uma abordagem para o estudo da exploração turística é a análise da paisagem que permite um melhor aproveitamento e planejamento da aptidão dos recursos naturais (Conti, 2003).

A paisagem consiste no produto comercial do turismo, o que torna a sua representação e a análise uma necessidade básica para o seu desenvolvimento (Moura et al. 2006). O mapeamento das unidades de paisagem considera os atributos abióticos, bióticos e antrópicos (Bertrand, 1978; Bolós, 1981), ou seja, efetua uma síntese cartográfica dos diferentes temas que compõe a paisagem, como: geologia, clima, geomorfologia, pedologia, vegetação e uso da terra (Martins et al., 2002).

O objetivo desse trabalho é definir as Unidades de Paisagem para fins turísticos do Parque Nacional da Serra dos Órgãos. Neste propósito foram utilizados estudo de campo, técnicas de processamento digital de imagens de satélite e análise do modelo digital de terreno (MDT). Com o propósito de avaliar a distribuição dos pontos turísticos levantados realizou-se uma avaliação dos seus posicionamentos nas unidades de paisagem.

\section{2 - Unidade de paisagem e o seu emprego no ecoturismo}

\subsection{Conceituação de Paisagem}

São várias as definições do termo paisagem. Considerando a etimologia das palavras paisagem (origem latina) e landscape (origem germânica) observam-se sentidos similares para os seus núcleos pais e land ('região', 'terra', 'território') e diferenciação em relação aos sufixos -agem ("conjunto, coleção, classes" ou "ação, resultado de ação") e -cape ("cobertura, o que cobre" ou "descrição, o que descreve"). Portando, do ponto de vista etimológico, paisagem (ou landscape) engloba a descrição das características estáticas e dinâmicas de uma determinada região, nos aspectos naturais e culturais (Martins et al., 2002).

O termo "paisagem" foi introduzida na ciência pelo geobotânico, Alexander von Humboldt, no início do século XIX, no sentido de "característica total de uma região terrestre" (Metzger, 2001). O seu conceito na ciência é aprofundado dentro de várias proposições onde se destacam: ecologia da paisagem (Troll, 1971), geossistemas (Sotchava, 1977), ecodinâmica (Tricart, 1977, 1979) e geografia física global (Bertrand, 1971).
As ciências apresentam diferentes conceitos de paisagem. Normalmente, a paisagem é definida como "a impressão global obtida da observação da Terra, a partir de uma distância razoável” (Brabyn, 1996). Esta definição pressupõe que a superfície da Terra observada é compreendida de forma integrada e sintética, sem fazer uma análise separada dos objetos específicos. Nesta abordagem, as paisagens são produtos da influência mútua de diversos fatores morfológicos, funcionais e cronológicos que se interagem e se modificam ao longo do tempo. Portanto podese estabelecer três principais enfoques do conceito de paisagem nos estudos científicos (Martins et al., 2002): (a) compreensão integrada da realidade; (b) relações espaciais (estrutura) e temporais (dinâmica e processos) definidas entre os diversos elementos e os vários níveis de observação (escala); e (c) definição de aspectos genéticos e de evolução (história). Portanto, a análise da paisagem apresenta tanto um enfoque de estudo morfológico integrado que a descreve e classifica, como também, um estudo de dinâmica que avaliam as suas funções e mudanças. No sentido de classificação, a paisagem pode ser considerada como "um segmento homogêneo do ambiente (inclusive a superfície da terra, o ar, e todos os recursos úteis), que sustentam todas as criaturas vivas" (Fabos, 1979). Na concepção da dinâmica de paisagem é necessário o desenvolvimento de estudos quantitativos de funcionamento ambiental, onde são considerados modelos estatísticos que consideram as variáveis espaciais e temporais, em diversas escalas (Veldkamp et al., 2001). Nesta abordagem as principais questões envolvem a determinação dos limites, dos processos chaves e das forças motrizes (driving forces) do sistema.

\subsection{Mapeamento das Unidades de Paisagem}

No mapeamento das unidades de paisagens, uma das primeiras proposições foi realizada por Troll (1966), que considerou como unidade o "ecótopo". No entanto, a sua definição é imprecisa e a hierarquização dos fatores não é evocada. Bertrand (1968) propôs uma taxonomia das paisagens considerando uma dominância dos fatores físicos e as seguintes condições: (a) a delimitação da unidade de paisagem não deve nunca ser considerada como um fim em si, mas somente como um intermédio de aproximação da realidade geográfica, (b) torna-se necessário delimitar diretamente a paisagem global, renunciando o emprego de uma média de unidades elementares; (c) o sistema taxonômico deve permitir classificar as paisagens em função da escala. A partir disso, Bertrand (1968) define um sistema de classificação hierárquica da paisagem em seis níveis (zona, domínio, região, geossistema, geofácies e geótopo). Essa taxonomia apresenta correspondência com o trabalho de Tricart (1965) que definiu um sistema de classificação em geomorfologia em oito níveis 
de grandeza espacial. A proposição do Tricart influência também a metodologia de mapeamento geomorfológico empregada no RADAM Brasil (Nunes et al., 1994) que considera cinco níveis taxonômicos (domínios morfoestruturais, região geomorfológica, unidades geomorfológicas, tipos de modelados e formações superficiais) e a proposta de Ross (1990) com seis táxons (unidades morfoestruturais, morfoesculturais, modelado, conjunto de formas semelhantes, dimensão de formas, formas lineares de relevo). Desta forma, a geomorfologia apresenta um caráter fundamental e integrador dos atributos ambientais.

No ambiente com relevo de alta amplitude topográfica o atributo geomorfológico se sobressai, ainda mais, devido a elevada correlação entre a geomorfologia e os demais atributos ambientais, como: microclima (irradiação, radiações incidentes, precipitação, temperatura do ar e do solo, pressão do vento e distúrbios meteorológicos), pedologia (movimento de massa, declive, intemperismo), vegetação e habitat (Ustin et al., 2004; Hoersch et al., 2002; Serrano et al., 2000). Neste tipo de ambiente o fator topográfico induz a formação de diferentes habitats ecológicos em uma distância relativamente próxima, proporcionando o desenvolvimento de um mosaico de paisagens com características próprias. Vários autores corroboram na descrição da influência da topografia na distribuição de florestas montanas: Florestas Tropicais (Sarmiento, 1986); Florestas Andinas (Skilenar \& Laegaard, 2003); Florestas Alpinas (Zimmermann \& Kienast, 1999) e em Florestas Subtropicais da América do Sul (Ellenberg, 1979). Nesta perspectiva, a geomorfologia torna-se um fator integrador na descrição das unidades de paisagens de ambientes escarpados. Além disso, a geomorfologia desempenha uma importante contribuição na delimitação das unidades de paisagem para o turismo, permitindo salientar as belezas naturais (rios, cachoeiras, lagos entre outros), como também, aprimorar a sua gestão (manejo, controle de erosão, previsão de enchurradas entre outros) (Guerra \& Marçal, 2005).

Na delimitação e descrição das unidades de paisagem normalmente são considerados os seguintes procedimentos: levantamento de dados, organização de bases cartográficas, elaboração de análises temáticas e representação destas informações. Normalmente, a falta de padronização dos dados disponíveis (diferentes escalas, épocas e metodologias de trabalho) torna necessária uma nova interpretação dos atributos da paisagem a partir da interpretação de imagens de sensores ópticos (Crepani et al., 2001).

O emprego do sensoriamento remoto, como uma referência integradora da paisagem, permite o acesso às relações de causa e efeito entre os elementos que a compõem. As imagens de satélite permitem uma visão sinóptica como diferentes análises conforme as características de resoluções da imagem (espacial, espectral, temporal e radiométrica). Barbosa (2003) adaptada a metodologia desenvolvida por
Crepani et al. (2001) de delimitação das unidades de paisagem com o propósito de desenvolver o ecoturismo.

Complementarmente as imagens de satélite podem ser utilizadas atributos de terreno provenientes do Modelo Digital de Terreno (MDT). As magnitudes dos processos atuantes na paisagem são sensíveis à posição no relevo e de suas variáveis morfométricas (Schmidt \& Dikau, 1998). O emprego da morfometria sempre foi uma importante ferramenta no estudo de bacias hidrográficas e na análise de vertentes (Gyle, 1961; Horton 1945; Melton, 1958; Strahler, 1952; Schumm, 1956). Com o advento de métodos computacionais houve um aprimoramento de procedimentos que descrevem os fenômenos ocorrentes na superfície terrestre, aumentando o seu emprego nas diversas áreas do conhecimento ambiental (Moore et al., 1991). Além disso, as técnicas de processamento digital de imagens, amplamente utilizadas para imagens de satélite, apresentam significativas contribuições quando utilizadas em imagens morfométricas com o propósito de evidenciar unidades distintas de geomorfologia e paisagem (Leal et al., 2003; Hermuche et al. 2002, 2003; Oliveira et al., 2005; Panquestor et al., 2002).

\section{3. Área de estudo}

A área de estudo está localizada nos municípios de Teresópolis, Petrópolis, Guapimirim e Magé na região serrana do Estado do Rio de Janeiro (Figura 1) abrangendo uma área de 10.600 hectares (IBDF, 1980). Essa área é parte das seguintes cartas topográficas do IBGE em escala 1:50.000: Itaipava (SF23-Z-B-I-4), Teresópolis (SF-23-Z-B-II-3), Petrópolis (SF-23Z-B-IV-2) e Itaboraí (SF-23-Z-B-V-1).

O clima é mesotérmico brando superúmido com temperatura média anual variando de $13^{\circ}$ a $23^{\circ} \mathrm{C}$, umidade relativa do ar de 80 a $90 \%$ e índice pluviométrico médio de $2.000 \mathrm{~mm}$. Possui verões brandos, sem estação seca, caracterizado pela abundância de precipitações nos meses de outubro a março, nos quais concentram cerca de 70 a $80 \%$ das precipitações e inverno com temperaturas e pluviosidade menores, atingindo o mínimo entre os meses de junho e julho (Nimer, 1977).

A geologia é representada por litologias pré-cambrianas e eopaleozóicas individualizadas nas seguintes unidades de mapeamento: (a) Complexo Rio Negro, que congrega migmatitos heterogêneos e biotita gnaisses graníticos; (b) Batólito Serra dos Órgãos, representado por biotita granitos e granodioritos gnáissicos; (c) leucogranitos gnáissicos, e (d) granitos pós-colisionais (granitos Andorinha e Nova Friburgo) (Ferrari et al., 1981; Penha et al., 1979, 1981; Pinto et al., 1980).

As duas principais propostas de mapeamento geomorfológico presentes na área são referentes à Dantas (2000) e a Silva (2002) na escala 1:250.000. O PARNASO está 


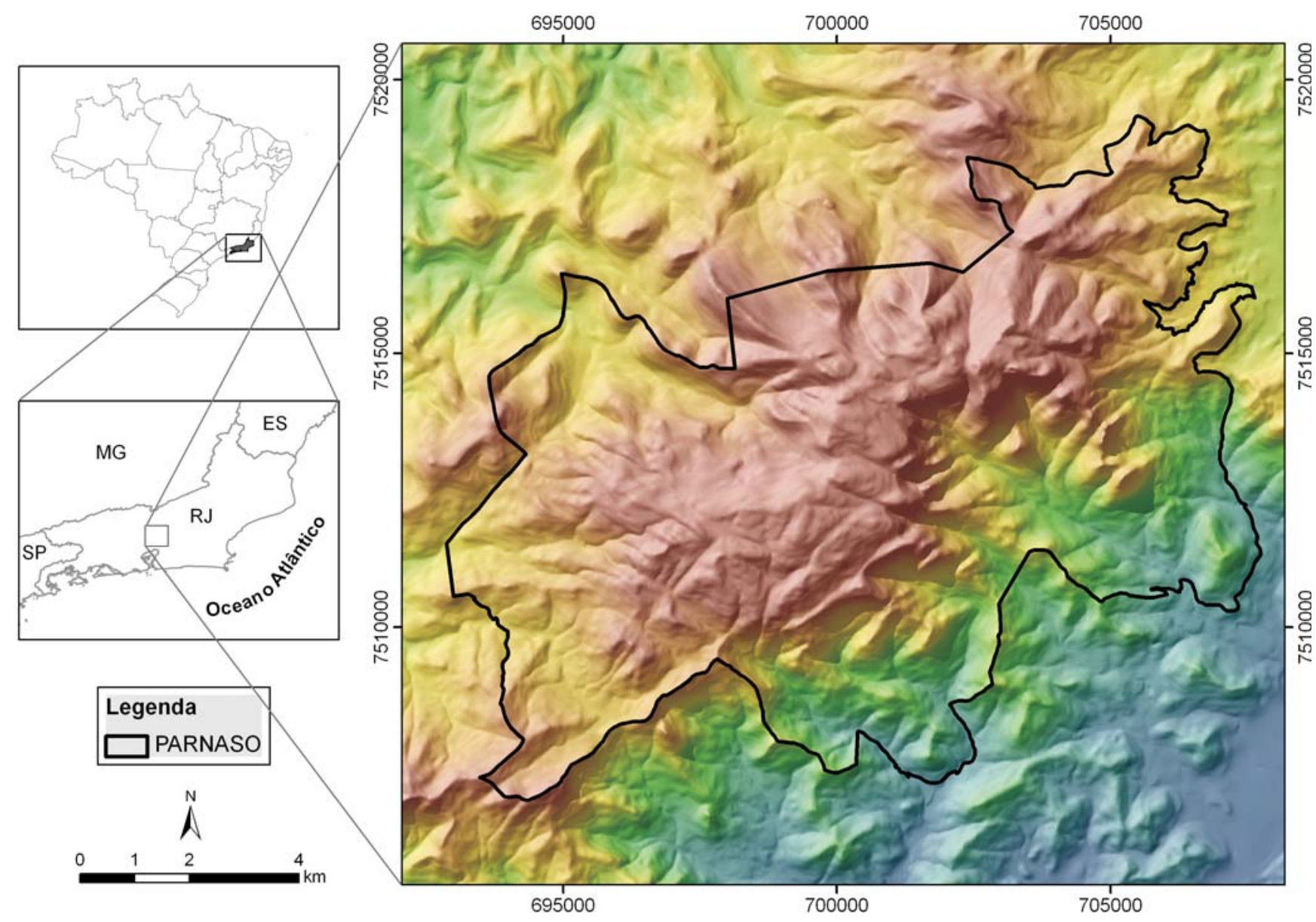

Figura 1 - Localização da área de estudo.

contido no Domínio Morfoestrutural do Planalto Atlântico e no Domínio das Depressões Tectônicas MesozóicoCenozóicas. Esses domínios subdividem-se na escala 1:250.000 nas Regiões do Planalto e Escarpas da Serra dos Órgãos e na Região do Rift da Guanabara, (Silva, 2002 e 2003).

A vegetação é representada pelas formações florestais e campestres. A formação florestal é representada pela Floresta Perenifólia Higrófila Costeira, tendo a sua ocorrência fortemente ligada ao relevo, a pluviosidade e a umidade (Alonso, 1977). Até as cotas de 1.500 - 1.800 metros predominariam árvores com altura de 20 a 25 metros, e, em cotas superiores, as árvores atingiriam de 12 a 15 metros de altura. A formação campestre, também conhecida como Campos de Altitude, é caracterizada como sendo áreas cobertas por vegetações herbáceas, muitas vezes contínuas, em meio à qual podem aparecer arbustos isolados ou em tufos, além da presença de liquens e musgos (Martinelli, 1989; Alonso, 1977).

O plano de manejo do PARNASO divide sua área em nove zonas com diferentes restrições de uso (Tabela 1, Figura 2), sendo que as atividades turísticas são realizadas nas seguintes áreas: Zona Primitiva, Uso Extensivo, Uso Intensivo e Histórico-Cultural que representam 49,05\% do parque. As atrações turísticas incluem centros de visitantes, museu, áreas de lazer com piscina e bosque, trilhas, cachoeiras, pontos de escalada e rappel como o Dedo de Deus, Escalavrado, Agulha do Diabo, Big Wall Pedra do Sino entre vários outros.

\section{Metodologia}

No presente trabalho a delimitação das Unidades de Paisagem foi realizada pela análise e interpretação visual conjunta das imagens de sensores ópticos e dos atributos de terreno com checagem e averiguação em campo. O mapeamento foi realizado para a área de estudo considerando duas escalas de trabalhos, que consiste na taxonomia de Bertrand (1968) na região natural e geossistema. A metodologia adotada pode ser subdividida em três etapas: (a) interpretação de imagens de sensores ópticos, (b) processamento digital dos atributos de terreno, e (c) levantamento dos atrativos turísticos. 


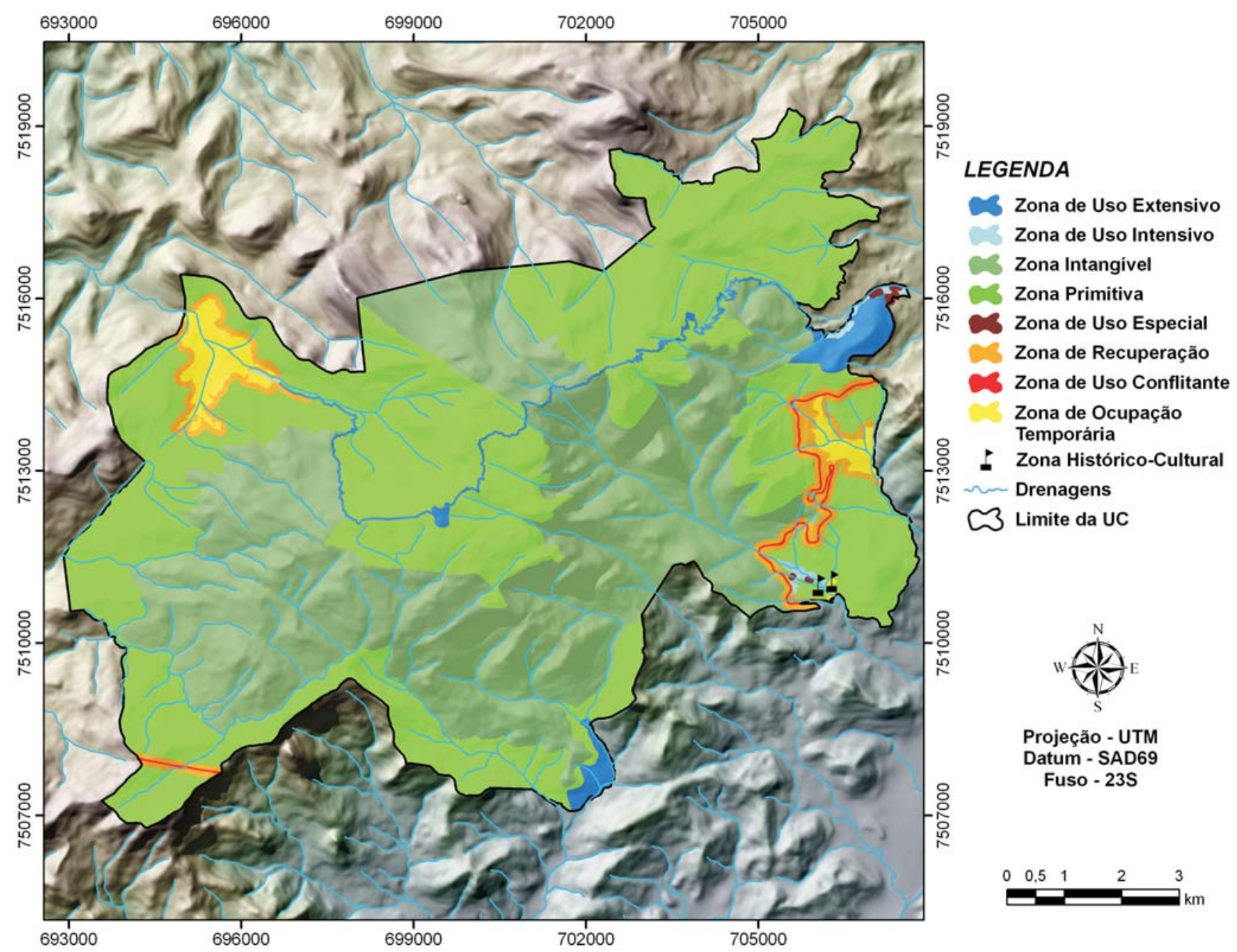

Figura 2 - Zoneamento do Parque Nacional da Serra dos Órgãos.

\subsection{Interpretação de imagens de sensores ópticos}

Nesse trabalho buscou-se integrar a resolução espectral do sensor Advanced Spaceborne Thermal Emission and Reflection Radiometer (ASTER) (setembro de 2004) com a alta resolução espacial do mosaico de fotos aéreas digitais ortorretificadas em preto e branco de 1999 na escala 1:10.000.

O sensor ASTER é resultado da cooperação entre a NASA - Earth Observing System (EOS), o Japan's Ministry of Economy, Trade and Industry (METI) e o Earth Remote Sensing Data Analysis Center (ERSDAC). Os dados desse sensor vêm sendo utilizados em análises de temperatura, emissividade, reflectância e elevação da superfície do terreno. Este sensor consiste de três subsistemas: (a) visível e infravermelho próximo (VNIR - $0,5 \mu \mathrm{m}-0,9 \mu \mathrm{m}$ ), constituído por três bandas espectrais com resolução de 15 metros; (b) infravermelho de ondas curtas (SWIR - 1,6 $\mu \mathrm{m}-2,5 \mu \mathrm{m}$ ), com nove bandas espectrais de resolução espacial de 30 metros; e (c) infravermelho termal (TIR), com cinco bandas espectrais de resolução espacial de 90 metros (Abrams, 2000; Fujisada et al., 1998; Yamaguchi et al., 1998). No presente trabalho foi utilizado o produto ASTER07, onde as imagens já estão corrigidas do efeito atmosférico (Thome et al., 1998). Na imagem ASTER a resolução espacial das imagens do infravermelho próximo (SWIR) foi duplicada com o objetivo de compatibilizar com a resolução do visível (VNIR). Este procedimento permitiu a integração das nove bandas em uma única imagem com resolução espacial de quinze metros. A classificação espectral foi realizada a partir da aplicação do método Spectral Correlation Mapper (SCM) (Carvalho \& Meneses, 2000).

Após a classificação espectral da imagem ASTER, realizou-se um refinamento dos limites das unidades de paisagem por interpretação visual de fotografias aéreas. A interpretação visual foi realizada pelo reconhecimento dos elementos básicos da fotografia referentes à textura, forma $\mathrm{e}$ padrão (Politano, 1994). 
Identificação de unidades de paisagem e sua implicação para o ecoturismo do PARNASO

Tabela 1: Zoneamento, restrições de usos, área e proporção em relação à UC (ICMBio, 2007).

\begin{tabular}{|c|c|c|c|}
\hline Zona & Restrições de usos & $\begin{array}{c}\text { Área } \\
\text { (hectares) }\end{array}$ & $\begin{array}{c}\text { Proporção } \\
\text { da UC }\end{array}$ \\
\hline Intangível & $\begin{array}{l}\text { Representa o mais alto grau de preservação, onde não é } \\
\text { permitida a visitação; as atividades humanas são limitadas } \\
\text { à pesquisa, ao monitoramento e à fiscalização, exercidas } \\
\text { somente em casos especiais. }\end{array}$ & $4.857,9$ & $45,60 \%$ \\
\hline Primitiva & $\begin{array}{l}\text { Permite pequena ou mínima intervenção humana, } \\
\text { contendo espécies da flora e da fauna ou fenômenos } \\
\text { naturais de grande valor científico. As atividades } \\
\text { permitidas são a pesquisa, o monitoramento ambiental, a } \\
\text { visitação nas trilhas existentes e a fiscalização. }\end{array}$ & $4.943,4$ & $46,40 \%$ \\
\hline $\begin{array}{l}\text { Uso } \\
\text { Extensivo }\end{array}$ & $\begin{array}{l}\text { É constituída em sua maior parte por áreas naturais, } \\
\text { podendo apres entar algumas alterações humanas. Tem a } \\
\text { função de propiciar atividades de uso público como } \\
\text { conscientização ambiental, interpretação e recreação com } \\
\text { baixa intensidade de impacto. }\end{array}$ & 242,2 & $2,27 \%$ \\
\hline $\begin{array}{l}\text { Uso } \\
\text { Intensivo }\end{array}$ & $\begin{array}{l}\text { Constituída por áreas naturais ou alteradas pelo homem. O } \\
\text { ambiente é mantido o mais próximo possível do natural, } \\
\text { podendo conter centro de visitantes, museus, outras } \\
\text { facilidades e serviços. }\end{array}$ & 40,5 & $0,38 \%$ \\
\hline $\begin{array}{l}\text { Histórico- } \\
\text { Cultural }\end{array}$ & $\begin{array}{l}\text { É aquela onde são encontradas amostras do patrimônio } \\
\text { histórico/cultural ou arqueopaleontógico, que serão } \\
\text { preservadas, estudadas, restauradas e interpretadas para o } \\
\text { público, servindo à pesquisa, educação e uso científico. }\end{array}$ & 0,01 & $0,00 \%$ \\
\hline $\begin{array}{l}\text { Uso } \\
\text { Conflitante }\end{array}$ & $\begin{array}{l}\text { Constitui-se em espaços localizados dentro de uma } \\
\text { Unidade de Conservação, cujos usos e finalidades, } \\
\text { estabelecidos antes da criação da Unidade, conflitam com } \\
\text { os objetivos de conservação da área protegida (gasodutos, } \\
\text { oleodutos, linhas de transmissão, antenas, captação de } \\
\text { água, barragens, estradas, cabos óticos e outros). }\end{array}$ & 11,3 & $0,11 \%$ \\
\hline $\begin{array}{l}\text { Ocupa ção } \\
\text { Temporária }\end{array}$ & $\begin{array}{l}\text { Locais com concentrações de populações humanas } \\
\text { residentes e suas respectivas áreas de uso. Zona } \\
\text { provisória, uma vez realocada a população, será } \\
\text { incorporada a uma das zonas permanentes. }\end{array}$ & 220,8 & $2,07 \%$ \\
\hline $\begin{array}{l}\text { Zona de } \\
\text { Recuperação }\end{array}$ & $\begin{array}{l}\text { Áreas consideravelmente antropizadas, uma vez } \\
\text { restaurada, será incorporada novamente a uma das zonas } \\
\text { permanentes. As espécies exóticas introduzidas deverão } \\
\text { ser removidas e a restauração deverá ser natural ou } \\
\text { naturalmente induzida. }\end{array}$ & 336,6 & $3,16 \%$ \\
\hline $\begin{array}{l}\text { Uso } \\
\text { Especial }\end{array}$ & $\begin{array}{l}\text { É aquela que contêm as áreas neces sárias à administração, } \\
\text { manutenção e serviços da Unidade de Conservação, } \\
\text { abrangendo habitaçôes, oficinas e outros. }\end{array}$ & 0,82 & $0,01 \%$ \\
\hline Total & & $10.653,5$ & $100,00 \%$ \\
\hline
\end{tabular}

\subsection{Processamento digital dos atributos de terreno}

Os dados de atributos de terreno podem ser obtidos a partir do MDT. A confecção do MDT da área em estudo utilizou a base cartográfica na escala 1: 50.000, em formato digital, contendo curvas de nível, pontos cotados e hidrografia. Esses dados foram corrigidos e posteriormente interpolados pelo módulo TOPOGRID do programa ArcInfo (ESRI, 1998). Esse procedimento emprega o algoritmo desenvolvido por Hutchinson (1989) que objetiva criar um
MDT para estudos hidrológicos. O algoritmo foi elaborado para produzir um MDT acurado, contendo tanto as propriedades das drenagens e os dados de direção de fluxo, quanto à remoção de dados espúrios relativos a pontos de depressões ou de elevações e uma técnica de interpolação por diferenças finitas. O MDT foi confeccionado com uma resolução espacial de dez metros e a partir dele foram gerados os atributos de terreno aspecto, declividade e área de contribuição. No presente trabalho foram utilizadas as seguintes técnicas de processamento digital nas imagens dos 
atributos de terreno que auxiliaram a interpretação visual: (a) composição colorida e (b) análise do histograma de freqüência.

A composição colorida (constituída de três bandas) permite sintetizar, numa única imagem, uma grande quantidade de informação. No presente trabalho para definir padrões tonais e texturais que caracterizam ambientes distintos foram realizadas combinações coloridas com os seguintes atributos de terreno: hipsometria, aspecto, declividade e área de contribuição. A partir das composições coloridas foi realizada a identificação das unidades de paisagem por interpretação visual diretamente na tela do computador.

De forma auxiliar foram utilizados histogramas de freqüência que representa na forma gráfica a quantidade de pixels para cada valor existente na imagem. Nas imagens morfométricas são evidenciadas rupturas do relevo que fornecem indicativos para delimitação das Unidades de Paisagem.

\subsection{Levantamento dos atrativos turísticos}

O levantamento dos pontos com potencial para ecoturismo é feito, basicamente, tomando-se nota das coordenadas geográficas pelo GPS de navegação, coleta de informações locais e registro fotográfico de interesse. Os atrativos foram selecionados principalmente pela beleza cênica natural onde se insere em uma topografia movimentada, com trilhas, áreas de acampamento, mirantes, cavernas, grutas, piscinas naturais, cumes e áreas com práticas de rapel. Os atrativos turísticos considerados no presente trabalho são os validados pelo parque e presente no plano de manejo como de utilização turística (ICMBio, 2007).

\section{Resultados}

A classificação do sensor ASTER permitiu evidenciar os seguintes alvos: (a) vegetação fotossinteticamente ativa (VFA), (b) vegetação não fotossinteticamente ativa (VNFA), (c) mistura entre VFA e VNFA, e (d) sombra. Desta forma, foram identificados principalmente áreas de floresta em relação às porções de afloramentos rochosos e campos de altitude (Figura 3). As fotografias aéreas permitiram detalhar a classificação da imagem ASTER evidenciando os contornos das seguintes classes: (a) dossel de árvores em ambientes florestais (formas irregulares, com presença de sombra e tonalidades escura); (b) escarpas íngremes (feições linerares limitando áreas de tonalidade claras de afloramento rochoso e sombreadas referente a escarpa de falha); (c) regiões de afloramentos rochosos (textura lisa e com tonalidades mais claras) e de vegetação rasteira campestre (textura aveludada fina e tonalidades médias); (d) áreas de relevo movimentado com formações tipo "pão de açúcar" (relevo residual

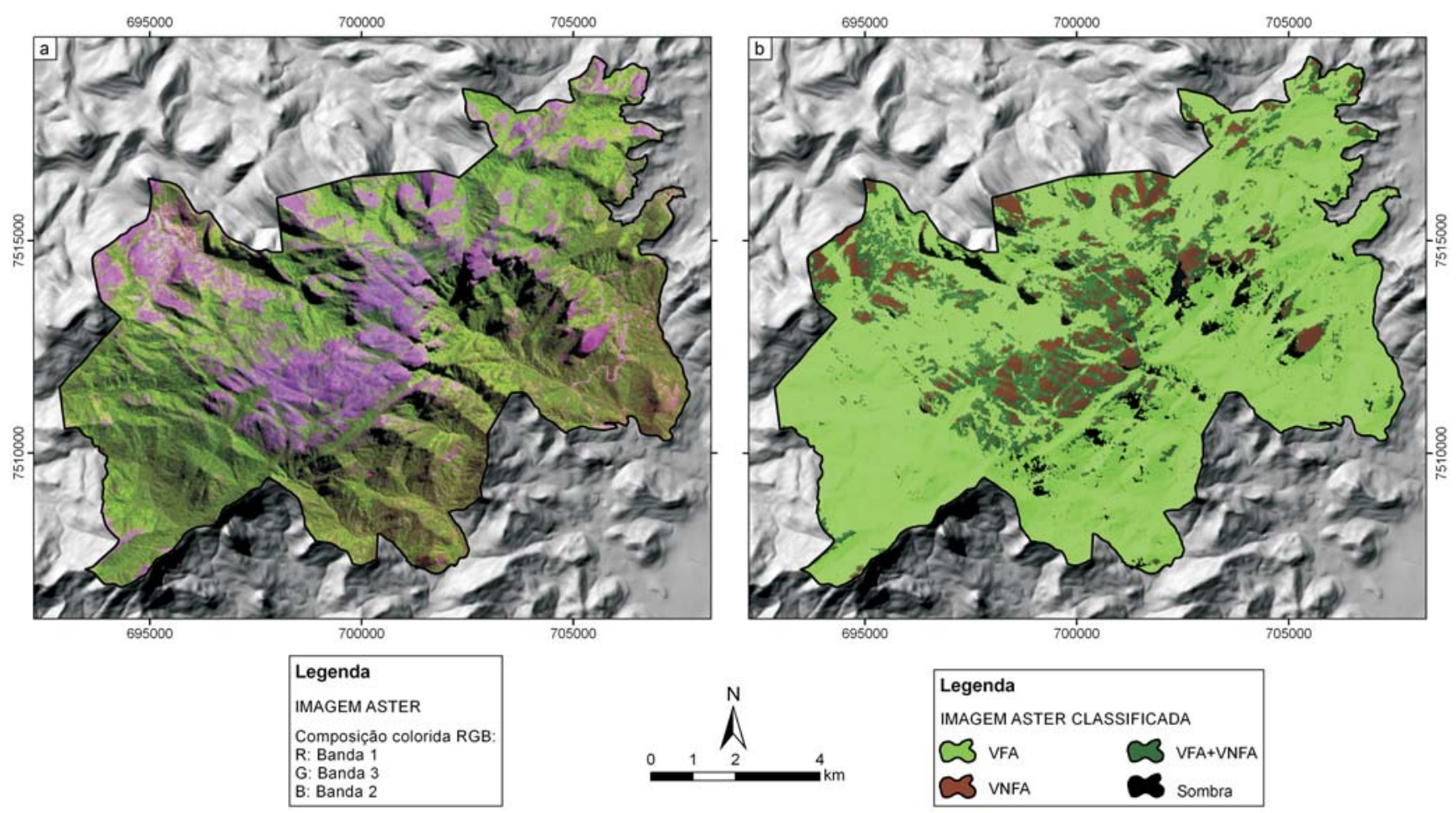

Figura 3 - (a) Imagem ASTER composição RGB:132 e (b) classificação da imagem ASTER considerando as seguintes classes: vegetação fotossinteticamente ativa (VFA), vegetação não fotossiteticamente ativa (VNFA), mistura entre VNF e VNFA e sombra. 

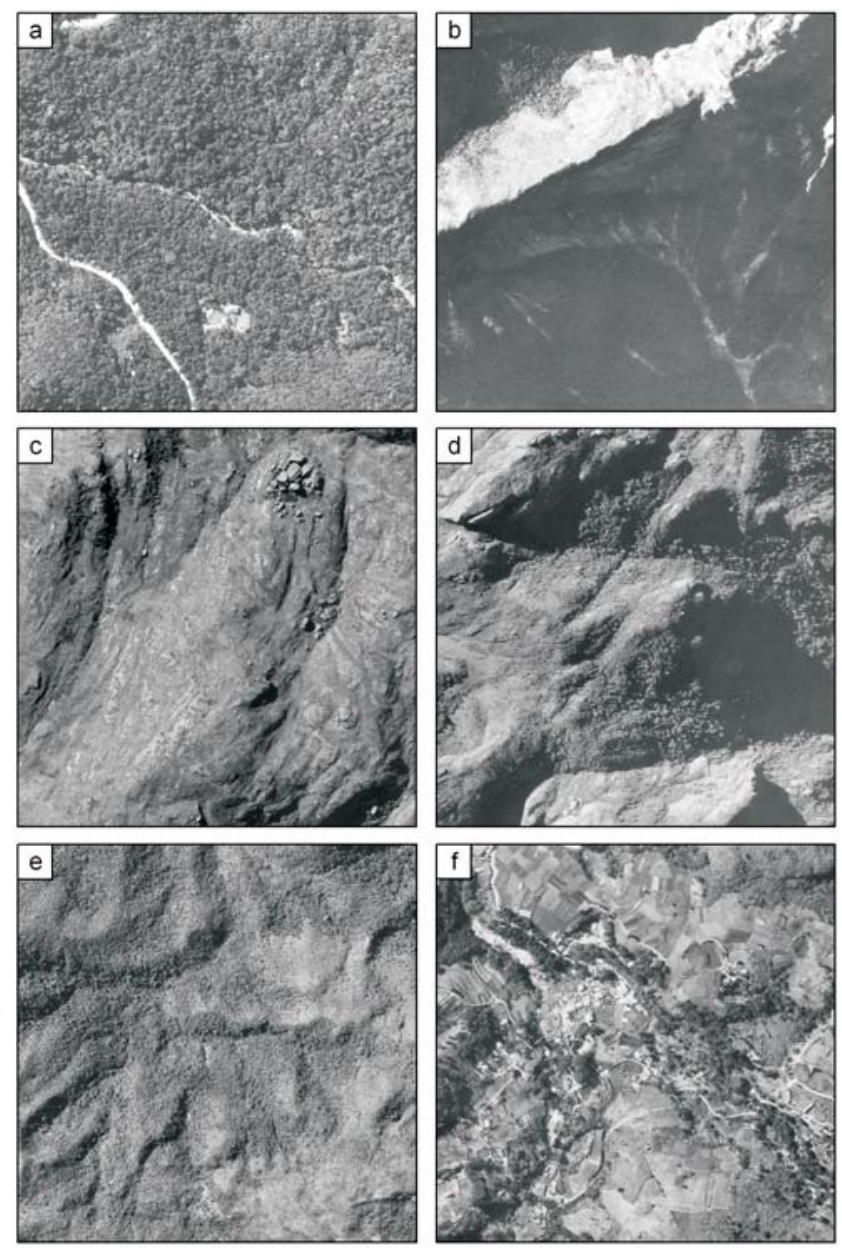

Figura 4-Padrões evidenciados na fotografia aérea: (a) ambientes florestais; (b) escarpas íngremes com presença de sombra, (c) regiões de afloramentos rochosos e campos de altitude, (d) áreas de relevo movimentado com formações tipo "pão de açúcar" e sistema de drenagem em zonas de falhas, (e) áreas com relevo dissecado; $e$ (f) vales com presença de uso agrícola.

pronunciado apresentando variações na tonalidade e na textura provenientes da diferença do sombreamento e da vegetação, formações florestais na base para as campestre no topo), e (e) áreas dissecadas; (f) áreas antrópicas (formas regulares, ausência de sombras, muitas vezes machetada; tonalidades claras a esbranquiçadas) (Figura 4). As fotografias aéreas auxiliaram também na visualização das feições geomorfológicas provenientes de rupturas de relevo, lineamentos de falha e fraturas e formas das vertentes.

A composição colorida das imagens morfométricas realçou os fatores geomorfológicos (Figura 5). A interpretação visual desta imagem conciliado com os aspectos de vegetação salientados pelas imagens dos sensores ópticos foi possível estabelecer as Unidades de Paisagem em dois níveis hierárquicos: (a) região natural e (b) geossistema.

\subsection{Regiões Naturais}

Nesta escala de trabalho foram identificadas duas unidades Escarpa Serrana e o Planalto Serrano (Figura 6). Essas unidades correspondem com os estudos descritos por Dantas (2000) e Silva (2002).

\section{(a) Escarpa Serrana}

Esta unidade localiza-se nas partes sul e sudeste do Parque Nacional da Serra dos Órgãos com área de 3.637 hectares, com altitudes que variam de 200 a 2.263 metros e amplitude topográfica total de 2.063 metros (Figura 7). As declividades predominantes variam de $10^{\circ}$ a $60^{\circ}$, com pico de freqüência na ordem de $33^{\circ}$, sendo que em alguns pontos o desnível é abrupto (Figura 8).

Esta unidade está inserida na escarpa da serra do Mar que apresenta uma ampla extensão regional, atravessando praticamente todo o território do estado do Rio de Janeiro numa direção WSW-ENE, acompanhando o "trend" estrutural do substrato geológico. Esta escarpa estende-se do litoral norte do estado de São Paulo, sob denominação local de serra da Bocaina, até a serra do Imbé ou Desengano, às margens do rio Paraíba do Sul, próximo a campos e São Fidélis, no Norte Fluminense. As Escarpas Serranas evoluem a partir de uma frente de dissecação de bloco falhado (Asmus \& Ferrari 1978) fortemente relacionado com os condicionantes estruturais provenientes das fraturas e falhas e da erosão diferencial sobre as unidades geológicas.

Esta unidade apresenta alta dinâmica superficial tanto devida ao alto gradiente topográfico como também pelo intenso aporte hídrico proveniente das precipitações orográficas. As condições climáticas apresentam um papel preponderante na modelagem da paisagem, onde as escarpas consistem em uma importante barreira orográfica aos sistemas frontais, apresentando altos índices pluviométricos anuais, superiores a $2.000 \mathrm{~mm} /$ ano. Essa característica determina uma alta atividade hídrica com alta taxa de transposição de materiais e movimentos de massa. Neste contexto o processo de lixiviação é intenso nas posições positivas do relevo, como também, estabelece extensas áreas de depósitos na base das escarpas com espessos colúvios pedogenizados.

A exumação do plano de falha, que proporciona o recuo por erosão, ocorre preferencialmente sobre os lineamentos com direção principal WSW-ENE. Os falhamentos estruturais consistem em zonas de fraqueza que permitem a concentração do fluxo de água e a intensificação da incisão vertical das drenagens. A organização do sistema hidrográfico obedece aos condicionantes estruturais apresentando um padrão de drenagem retangular tipificado pela presença de ângulos retos. Assim, as zonas de falhas e fraturas tornam-se calhas naturais para a passagem de água salientando as suas conformações no relevo. 


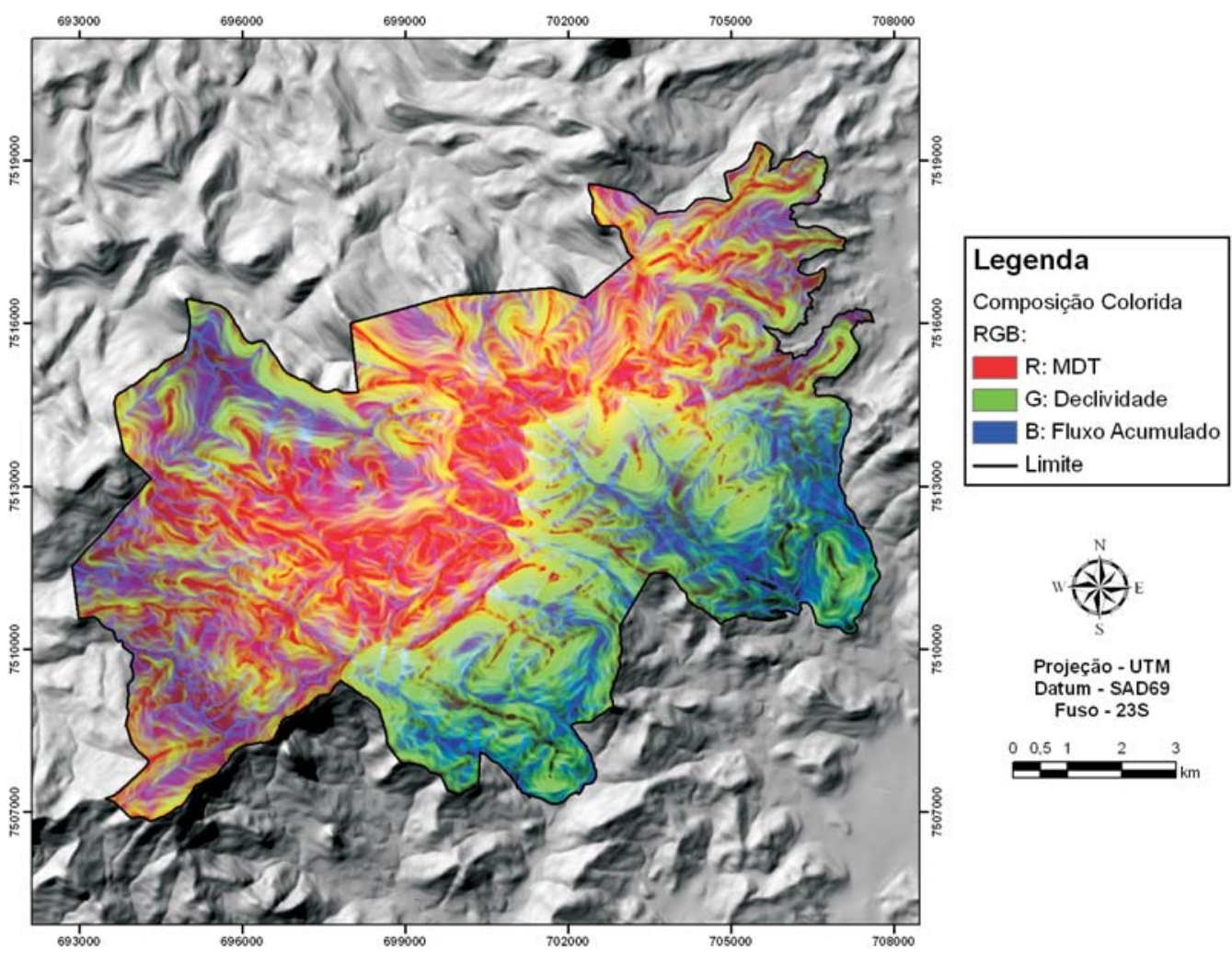

Figura 5 - Composição colorida dos atributos de terreno R: MDT/G:declividade/B:fluxo acumulado.

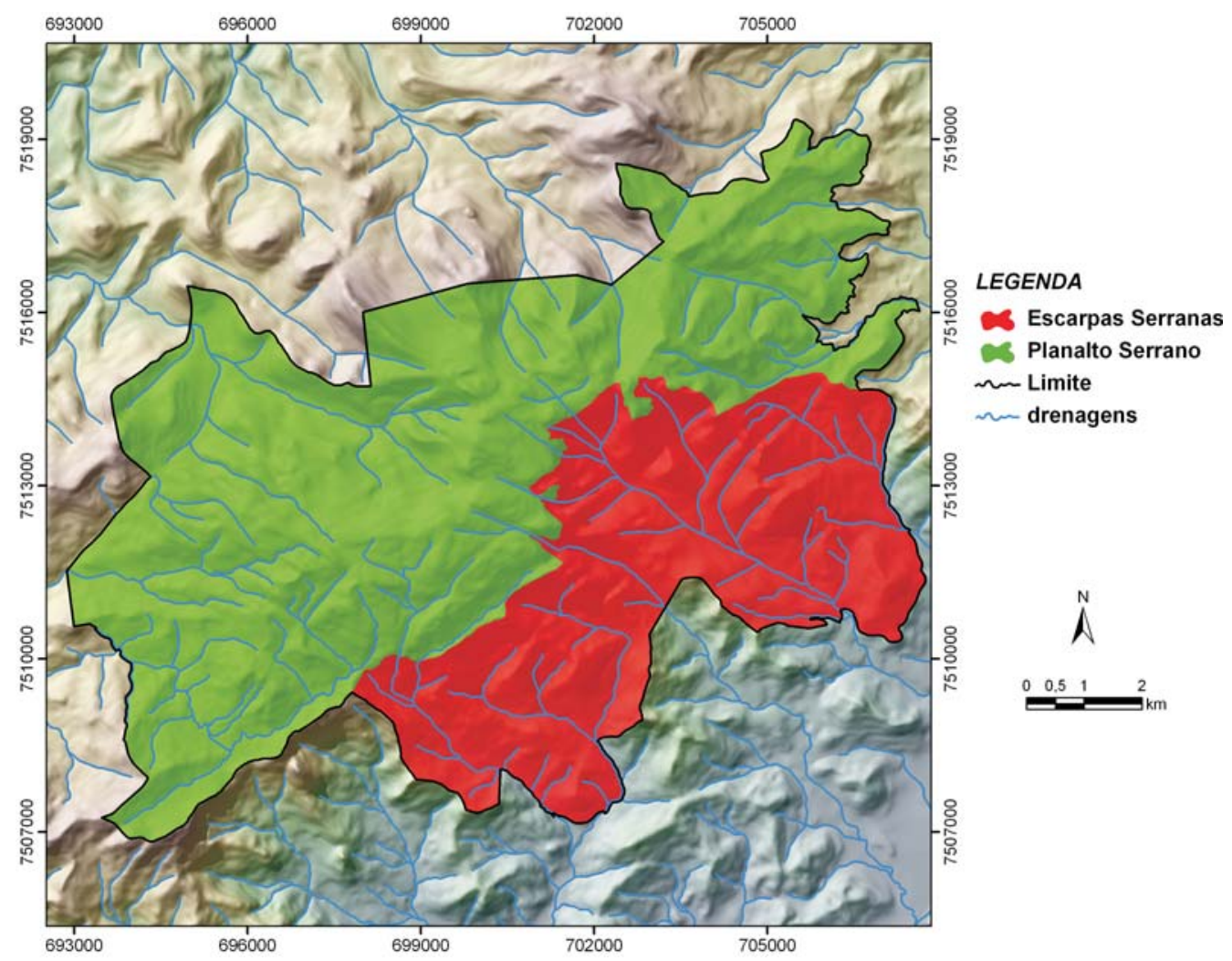

Figura 6 - Regiões Naturais do PARNASO. 


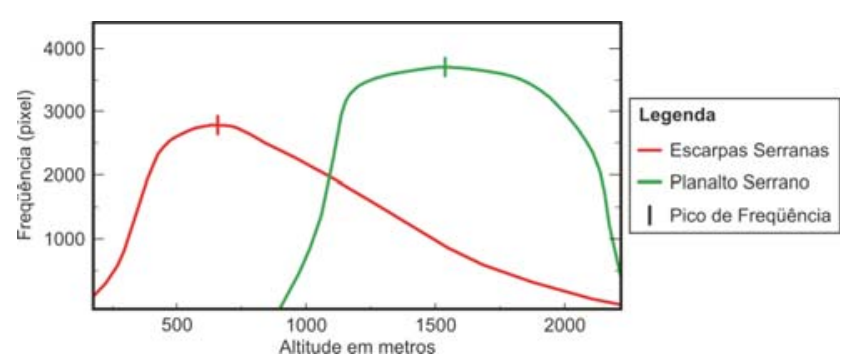

Figura 7 - Histograma de Freqüência com as altitudes em metros das Unidades de Paisagem (Regiões Naturais).

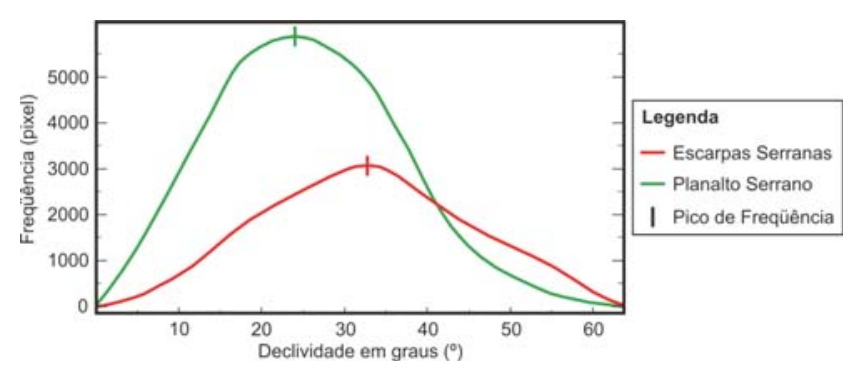

Figura 8 - Histograma de Freqüência com as declividades em graus das Unidades de Paisagem (Regiões Naturais).

Outro fator importante na modelagem do relevo é o processo de erosão diferencial provocado pela maior resistência das rochas graníticas, posicionadas na porção superior, com relação às rochas gnáissicas, posicionadas na porção inferior. $\mathrm{O}$ granito tem estrutura mais homogênea do que o gnaisse, que por sua vez, possui uma estrutura planar bem desenvolvida, que favorece a passagem da água pela rocha e, conseqüentemente, sua alteração/degradação. Portanto, o entalhamento do talvegue desencadeia de forma mais acelerada quando atinge as rochas gnáissicas, enquanto que as rochas graníticas tendem a manter a posição do relevo (Figura 9).

A erosão hídrica delineada pelo sistema hidrográfico promove uma erosão regressiva, promovendo ramificações de cursos de primeira ordem, gerando formas residuais, como morros testemunhos e cristas alinhadas mantidas e individualizadas por camadas lito-estruturais mais resistentes associadas às rochas graníticas. No modelado referente às cristas observa-se uma diferenciação das unidades litológicas onde estão presentes importantes atrativos turísticos como o Dedo de Deus, Escalavrado, entre outros.

Na evolução do relevo as camadas de rochas graníticas, com maior resistência litológica, são mobilizadas por solapamento do material subjacente, mais tenro, provocando o desmoronamento da camada superior. Desta forma, a

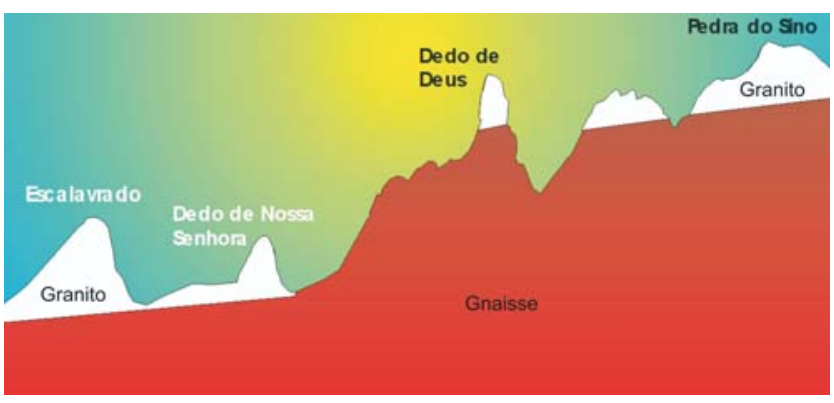

Figura 9 - Perfil da Serra dos Órgãos demonstrando a relação do substrato rochoso granítico com o posicionamento dos principais cumes (DRM, 2005).

retirada do material das rochas gnáissicas, mais friáveis, tornase também responsável pela exumação da superfície granítica. À medida que se afasta da frente de falha, nas porções mais baixas do relevo e onde predominam rochas gnáissicas, observa-se uma tendência para a abertura de vales mais planos permitindo um maior acúmulo de materiais e formação de solos mais profundos de característica alóctone (transportados).

A distribuição dos solos está intimamente relacionada com as feições tectônicas. Nas escarpas serranas observase, geralmente, solo pouco espesso e bastante lixiviado. As zonas com maiores declividades são referentes aos paredões subverticais onde as rochas estão aflorantes devido à impossibilidade de retenção do solo. Com a gradativa diminuição da declividade surge o desenvolvimento de solos incipientes e rasos. Na parte basal da escarpa torna-se freqüente a ocorrência de depósitos de tálus, com baixa capacidade de carga que permite a formação de vales mais planos onde se desenvolvem solos mais profundos. Assim, os ambientes variam tanto lateralmente como verticalmente evidenciando uma transição de afloramento rochoso, passando por solos rasos até a presença de solos profundos.

A dificuldade de acesso das áreas escarpadas da Serra do Mar permite a permanência de extensas áreas de mata atlântica ainda preservada. A cobertura vegetal possui uma estreita relação com os elementos morfológicos descritos, apresentando diferenciações conforme a posição no relevo. Na parte superior, onde ocorrem rochas graníticas tanto na região de cimeira, topos das cristas alinhadas ou morros testemunhos, a vegetação é predominantemente herbácea ou herbácea-arbustiva. Ao longo das escarpas ocorrem espécies pioneiras, enquanto que nas áreas de depósito de tálus e nos vales se desenvolvem a Mata Atlântica com espécies arbóreoarbustivas.

Todos esses terrenos, devido às características mencionadas acima, apresentam um alto potencial de ocorrência de movimentos de massa. Desta forma, estas áreas devem ser destinadas à preservação ambiental e ao ecoturismo. 


\section{(b) Planalto Serrano}

Esta unidade localiza-se nas partes oeste, noroeste, norte e nordeste do Parque Nacional da Serra dos Órgãos com área de 6.983 hectares, altitudes que variam de $910 \mathrm{a}$ $2.263 \mathrm{~m}$ e amplitude topográfica total de 1.353 metros (Figura 7). As declividades predominantes variam de $5^{\circ}$ a $45^{\circ}$, com pico de freqüência na ordem de $25^{\circ}$ (Figura 8). Esta unidade situa-se no reverso da Escarpa Serrana, analisada anteriormente e corresponde à parte soerguida da Serra do Mar, abrangendo as áreas de maiores altitudes, como o topo e a vertente continental, que mergulha mais suavemente para a calha do rio Paraíba do Sul.

O Planalto Serrano, formado por granitos, biotita granitos granodioritos gnáissicos e migmatitos; evolui a partir de dois sistemas de falhas principais com direções sudestenoroeste e sudoeste-nordeste. Os lineamentos tornam-se zonas preferenciais para os principais cursos d'água.
As distribuições dos solos e da vegetação estão relacionadas à morfodinâmica onde nos locais em que há perda de material por escorregamentos planares/rotacionais e as corridas de massa ocorrem solos rasos e vegetação herbáceoarbustivas, enquanto que nas planícies fluviais onde há acumulação de material predominam solos espessos e espécies arbóreo-arbustivas. No topo da Serra dos Órgãos, em altitudes superiores a 1.900 metros desenvolvem uma associação de gramíneas e arbustos denominados de Campos de Altitude. Os Campos de Altitude do Rio de Janeiro somente estão presentes nessa formação do PARNASO, Planalto do Itatiaia e um pequeno remanescente na Serra do Desengano possuindo um alto grau de endemismo e um grande valor para a conservação.

\subsection{Geossitemas}

Considerando suas características morfodinâmicas a unidade da Escarpa Serrana pode ser dividida em duas

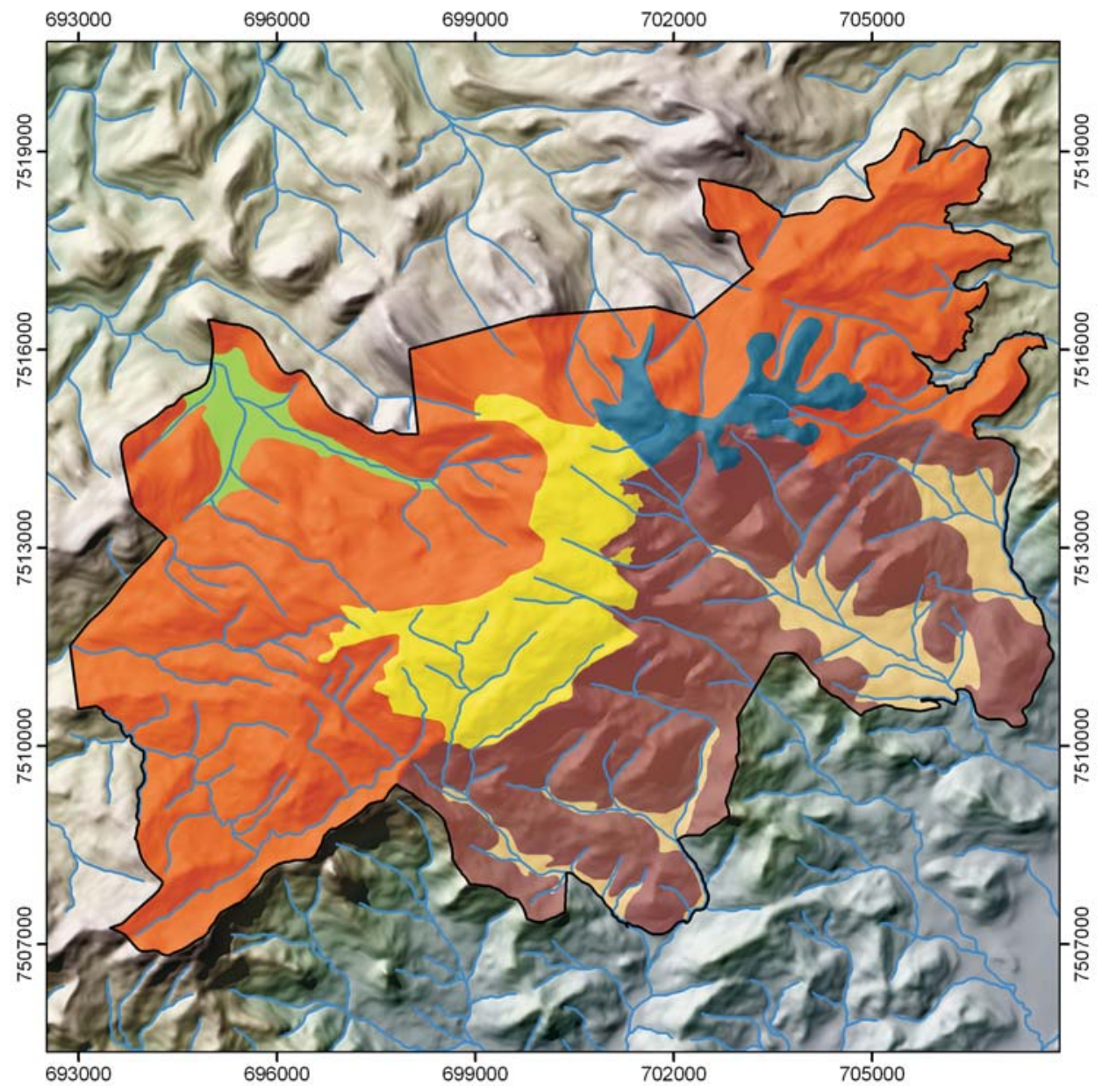

\section{LEGENDA}

\section{ESCARPA SERRANA}

3 Vales da Escarpa de Falha

$\checkmark$ Escarpa de Falha

\section{PLANALTO SERRANO}

Planalto do Açú

$\checkmark 3$ Planalto da Pedra do Sino

3 Planaltos Dissecados

Vale do Bonfim

$\sim$ Rios

$\sim$ Limite

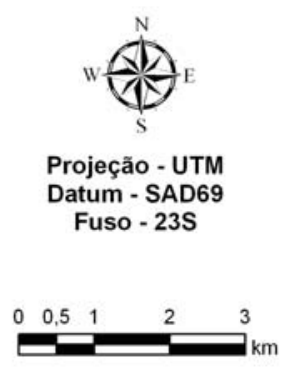

Figura 10 - Geossistemas do PARNASO. 
unidades: (a) Escarpa de Falha e (b) Vales Encaixados. Enquanto o Planalto Serrano pode ser subdividido em quatro unidades: (d) Planalto do Açu, (e) Planalto da Pedra do Sino, (f) Planaltos Dissecados, e (g) Vale do Bonfim (Figura 10). A síntese dos atributos de cada unidade da paisagem está na Tabela 2.

\section{(a) Escarpa de Falha}

A Escarpa de Falha localiza-se na parte central do Parque Nacional da Serra dos Órgãos com área de 2.941 hectares, altitudes variando de 196 a 2.210 metros (Figura 11). As declividades predominantes variam de $15^{\circ}$ a $60^{\circ}$ (Figura 12). Nesta unidade estão presentes os maiores desníveis topográficos referentes às vertentes abruptas com paredões rochosos subverticais. As áreas mais altas do relevo estão vinculadas à presença dos granitos que por serem mais resistentes à erosão formam estruturas positivas no relevo. Sofre intenso processo de dissecação com ocorrência constante de movimento de massa, consistindo em uma unidade fortemente instável. As atrações turísticas são as trilhas de acesso e os pontos de visitação do Escalavrado, Dedo de Nossa Senhora, Dedo de Deus e Cabeça de Peixe.

\section{(b) Vales da Escarpa de Falha}

Esta unidade ocorre preferencialmente nas partes sul e sudeste do Parque Nacional da Serra dos Órgãos. Esses vales caracterizam-se por serem encaixados com vertentes bastante dissecadas e íngremes com declividade predominantemente entre $10^{\circ}$ a $30^{\circ}$, com pico de freqüência em $18^{\circ}$ (Figura 12).

Na porção mais baixa do relevo ocorre diminuição da declividade, gerando fundos de vales entulhados de sedimentos. Esse processo decorre dos sucessivos eventos de movimentos de massa nas paredes escarpadas dos vales, que promovem o seu recuo e a formação de depósitos no sopé. Conseqüentemente, os solos são mais profundos derivados de espessos colúvios pedogenizados, o que permite o desenvolvimento de vegetação arbórea.

Observa-se a presença humana em um dos vales dessa unidade, denominado de Vale do Garrafão. A ocupação desse vale é devido às características ambientais de ser relativamente mais plana e de menor altitude. A comunidade possui cerca de 90 habitações, onde predominam casas de alto padrão de veraneio e sítios. Conforme ICMBio (1997) essa apropriação indevida é originária da indefinição dos limites da UC até 1984 que facilitou o loteamento da área na década de 1950. Desta forma, essa área apresenta como um dos principais problemas as invasões e o crescimento desordenado da comunidade.

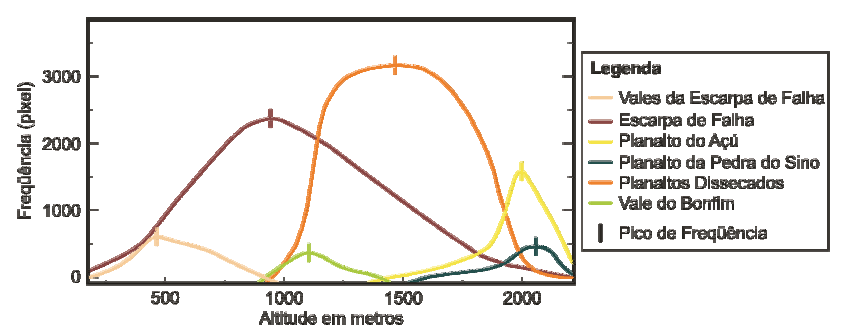

Figura 11 - Histograma de Freqüência com as altitudes em metros das Unidades de Paisagem (Geossistema).

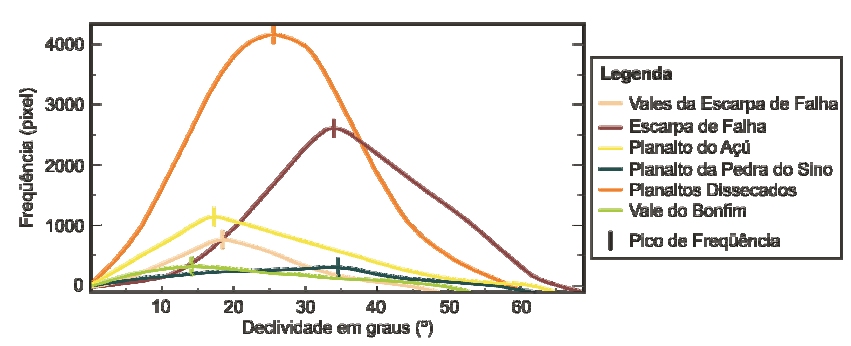

Figura 12 - Histograma de Freqüência com as declividades em graus das Unidades de Paisagem (Geossistema).

\section{(c) Planalto do Açu}

O Planalto do Açú localiza-se na parte Central do Parque Nacional da Serra dos Órgãos com área de 1.057 hectares e variando de 1.557 metros a 2.263 metros (Figura 11). As declividades predominantes variam de $0^{\circ}$ a $55^{\circ}$, com pico de freqüência na ordem de $18^{\circ}$ (Figura 12).

O Planalto do Açu está posicionado na porção mais alta do relevo, sobre o Granito Andorinha que possui maior resistência ao processo intempérico em relação às demais unidades geológicas. Essa característica do substrato rochoso permite a formação de um extenso planalto onde à rede de drenagem e variações altimétricas estão vinculadas ao sistema de falhas. A intensa atividade hídrica proveniente das chuvas orográficas provoca um intenso transporte de materiais que ocasionam a exposição de afloramentos rochosos ou a existência, apenas, de solos incipientes. A combinação de resistência litológica e o processo da lixiviação das chuvas em clima frio proporcionam a formação de um ambiente singular onde são desenvolvidos os campos de altitude que consistem em um importante fator da paisagem e devido seu endemismo prioritário para a conservação. Portanto, podemos estabelecer uma forte relação ambiental onde a resistência das rochas correlaciona-se a uma área elevada, que provoca uma barreira orográfica aumentando o índice pluviométrico e a atividade hídrica, que ocasiona uma 
OLIVEIRA, S.N. et al.

Tabela 2 - Atributos das Unidades de Paisagem (Geossistema).

\begin{tabular}{|c|c|c|c|c|}
\hline Unidades & Geologia & $\begin{array}{c}\text { Aspecto } \\
\text { Geomorfológico }\end{array}$ & Solos & $\begin{array}{c}\text { Vegetação } \\
\text { /Uso }\end{array}$ \\
\hline $\begin{array}{l}\text { Vales da } \\
\text { Escarpa de } \\
\text { Falha }\end{array}$ & $\begin{array}{c}\text { Biotita granitos } \\
\text { granodioritos gnáissicos; } \\
\text { Leucogranitos } \\
\text { Gnáissicos; Migmatitos }\end{array}$ & $\begin{array}{c}\text { Depressões alongadas } \\
\text { em que no seu eixo } \\
\text { localiza-se o curso } \\
\text { d'água }\end{array}$ & Argissolos & $\begin{array}{l}\text { Floresta } \\
\text { Densa }\end{array}$ \\
\hline $\begin{array}{l}\text { Escarpa de } \\
\text { Falha }\end{array}$ & $\begin{array}{c}\text { Granito Andorinha; } \\
\text { Biotita granitos } \\
\text { granodioritos gnáissicos; } \\
\text { Leucogranitos } \\
\text { Gnáissicos; Migmatitos }\end{array}$ & $\begin{array}{l}\text { Trechos de transição } \\
\text { entre níveis } \\
\text { topográficos diferentes }\end{array}$ & $\begin{array}{l}\text { Neossolo } \\
\text { Litólic o; } \\
\text { Cambissolos; } \\
\text { Argissolos }\end{array}$ & $\begin{array}{l}\text { Arbustiva; } \\
\text { Floresta } \\
\text { Densa }\end{array}$ \\
\hline $\begin{array}{l}\text { Planalto do } \\
\text { Açú }\end{array}$ & $\begin{array}{l}\text { Granito Andorinha; } \\
\text { Biotita granitos } \\
\text { granodioritos gnáissicos }\end{array}$ & $\begin{array}{c}\text { Áreas contíguas } \\
\text { localizadas no topo } \\
\text { serrano }\end{array}$ & $\begin{array}{l}\text { Neossolo } \\
\text { Litólico; } \\
\text { Cambissolo }\end{array}$ & $\begin{array}{l}\text { Campos } \\
\text { de } \\
\text { Altitude }\end{array}$ \\
\hline $\begin{array}{c}\text { Planalto da } \\
\text { Pedra do Sino }\end{array}$ & Granito Andorinha & $\begin{array}{l}\text { áreas contíguas } \\
\text { localizadas no topo } \\
\text { serrano }\end{array}$ & $\begin{array}{l}\text { Neossolo } \\
\text { Litólico; } \\
\text { Cambissolo }\end{array}$ & $\begin{array}{l}\text { Campos } \\
\text { de } \\
\text { Altitude }\end{array}$ \\
\hline $\begin{array}{l}\text { Planaltos } \\
\text { Dis secados }\end{array}$ & $\begin{array}{c}\text { Biotita granitos } \\
\text { granodioritos gnáissicos; } \\
\text { Migmatitos }\end{array}$ & $\begin{array}{c}\text { Áreas do topo serrano, } \\
\text { voltados para o } \\
\text { continente, } \\
\text { intensamente } \\
\text { dissecadas }\end{array}$ & $\begin{array}{l}\text { Neossolo } \\
\text { Litólico; } \\
\text { Cambissolo }\end{array}$ & $\begin{array}{l}\text { Rupestre, } \\
\text { Arbustiva } \\
\text { e arbórea }\end{array}$ \\
\hline Vale do Bonfim & $\begin{array}{l}\text { Biotita granitos } \\
\text { granodioritos gnáissicos }\end{array}$ & $\begin{array}{c}\text { Depressões alongadas } \\
\text { localizadas no interior } \\
\text { da unidade de } \\
\text { Planaltos }\end{array}$ & $\begin{array}{l}\text { Argissolos; } \\
\text { Cambissolos }\end{array}$ & Cultivos \\
\hline
\end{tabular}

forte lixiviação permitindo a formação de solos rasos onde se adaptam e formam os campos de altitude. Essas características demonstram um meio instável onde a morfogênese predomina sobre a pedogênese.

No Planalto do Açu as bacias de drenagem possuem vertentes direcionadas para a porção litorânea. O seu limite noroeste em direção ao vale do Paraíba demarca uma quebra do relevo e uma mudança litológica para rochas gnáissicas. As atrações turísticas dessa unidade são parte da Trilha da Travessia Petrópolis-Teresópolis e o ponto de visitação Castelos do Açú.

\section{(d) Planalto da Pedra do Sino}

O Planalto da Pedra do Sino localiza-se na parte nordeste do Parque Nacional da Serra dos Órgãos com área de 337 hectares, altitude variando de 1.550 metros a 2.263 metros e amplitude topográfica total de 713 metros (Figura 11). As declividades predominantes variam de 5 a $60^{\circ}$, com pico de freqüência na ordem de $35^{\circ}$ (Figura 12). Esta unidade apresentase no mesmo contexto geológico do Planalto do Açú posicionado sobre o granito Andorinhas. No entanto, nessa zona planáltica, o relevo é mais montanhoso. Os sistemas de drenagem nas zonas de falhas possuem maior incisão vertical e o relevo apresenta formações tipo "pão de açúcar". Esse planalto possui menor extensão que o planalto do Açu devido à maior dissecação do relevo em suas bordas. $\mathrm{O}$ clima é frio, os solos são rasos e lixiviados (Cambissolos e Neossolos Litólicos) com presença de campos de altitude. Como o planalto do Açu consiste em uma unidade instável que deve ser prioritariamente preservada. As atrações turísticas dessa unidade são: Trilha Pedra do Garrafão, Trilha Pedra de São Pedro, Trilha Caminho das Orquídeas, Trilha Agulha do Diabo, Trilha Pedra de São João, Trilha Travessia da Neblina, Pedra do Garrafão, Pedra do Sino, Pedra de São João, Pedra de São Pedro, Papudo, Nariz do Frade, Agulha do Diabo.

\section{(e) Planaltos Dissecados}

Os Planaltos Dissecados localizam-se nas partes oeste, noroeste, norte e nordeste do Parque Nacional da Serra dos Órgãos com área de 4.986 hectares e amplitude topográfica de 1.233 metros (entre 925 metros a 2.158 metros) (Figura 11). As declividades predominantes variam de 10 a $45^{\circ}$, com pico de freqüência na ordem de $25^{\circ}$ (Figura 12). Na borda Noroeste 

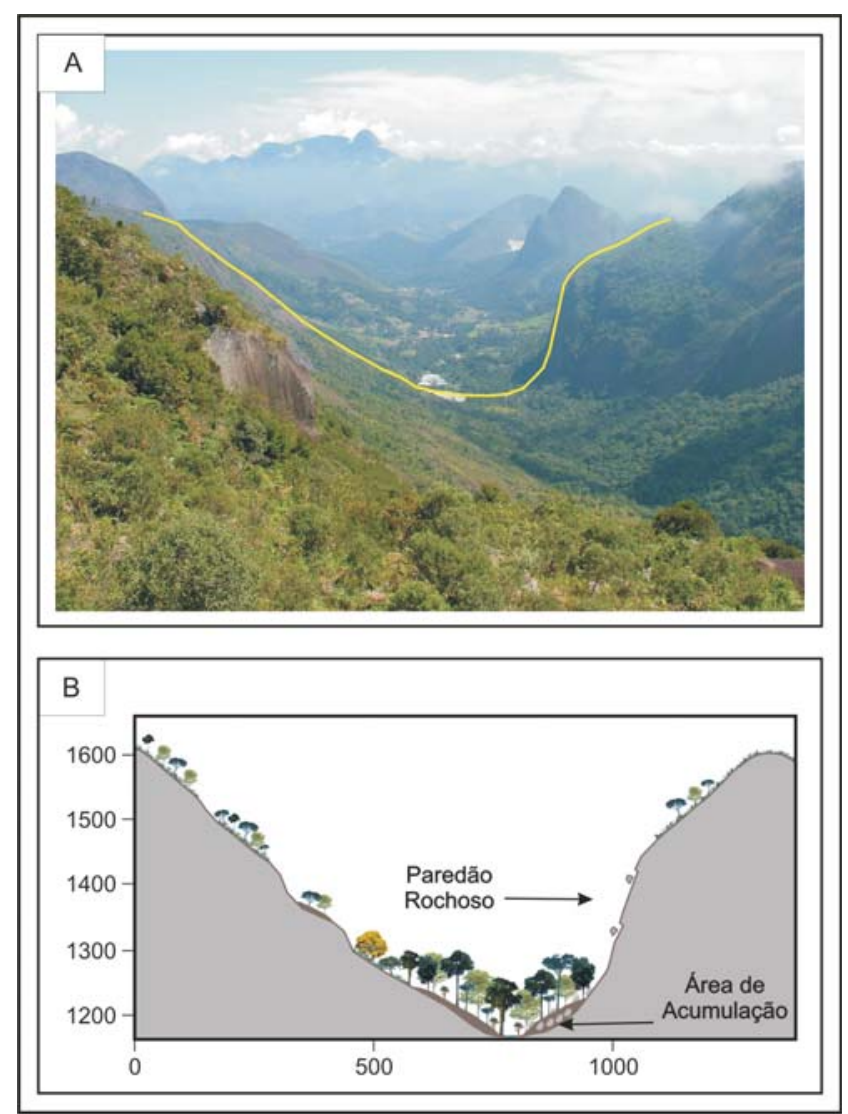

Figura 13 - Comportamento assimétrico do Vale do Bonfim.

do granito Andorinhas ocorre o contato com o gnaisse que por ser menos resistente ao intemperismo permite maior dissecação. Com relação às áreas típicas dos planaltos, essa unidade apresenta um sistema de drenagem com maior aprofundamento do talvegue e maior declividade. As atrações turísticas presentes são: trilha da travessia PetrópolisTeresópolis, trilha Mozart Catão, trilha Suspensa, Cachoeira do Alicate, Cachoeira Véu da Noiva de Teresópolis, e os pontos de visitação Poço Castelo e Bosque Santa Helena.

\section{(f) Vale do Bonfim}

O Vale do Bonfim localiza-se na parte noroeste do Parque Nacional da Serra dos Órgãos com área de 228 hectares, altitude variando de 910 a 1.405 metros e amplitude topográfica total de 495 metros (Figura 11). As declividades predominantes variam de $0^{\circ}$ a $40^{\circ}$, com pico de freqüência na ordem de $14^{\circ}$ (Figura 12).

Este vale possui um comportamento assimétrico onde uma de suas vertentes possui uma ruptura abrupta com paredões rochosos subverticais, enquanto a outra vertente apresenta uma declividade relativamente menor (Figura 13). $\mathrm{Na}$ base desses extensos paredões rochosos são descritos espessos depósitos de tálus dispostos em forma de rampas. Nestes depósitos pode-se constatar uma cobertura de alteração intempérica com formação de solos mais profundos provenientes de uma contínua decomposição de materiais e alteração das rochas com uma subseqüente pedogênese.

Nesta unidade observa-se a presença da ação antrópica que utiliza uma área de Ocupação Temporária de aproximadamente 101 hectares para o desenvolvimento de atividades de cultivo agrícola, principalmente, de hortaliças e flores. Conforme Rocha (2002), os moradores são predominantemente posseiros. As atrações turísticas são trilhas leves a moderadas e os pontos de visitação Poço Paraíso, Poço das Bromélias, Gruta do Presidente e Cachoeira Véu da Noiva de Petrópolis.

\subsection{Distribuição dos pontos turísticos nas unidades de paisagem}

O levantamento dos atrativos turísticos apresentou um total de 27 pontos. Os pontos turísticos estão concentrados e restritos, basicamente, em secções transversais que cortam a serra a partir das sedes de Petrópolis, Teresópolis e de Guapimirim (Figura 14). A existente aglutinação espacial dos atrativos permite um maior controle da visitação restringindo o uso turístico a apenas uma pequena porção do parque.

Desta forma, a maior parte do parque é mantida como área de preservação sem a presença do uso turístico que se justifica pela alta instabilidade e fragilidade ambiental desses ambientes. Apesar de o uso turístico ser restrito, observa-se que as unidades de paisagem apresentam-se bem representadas. A distribuição dos atrativos turísticos é relativamente homogênea (Tabela 3). Desta forma, o turista possui acesso à visitação aos diferentes tipos de beleza cênica presentes no parque. A única exceção é o Planalto do Açu com um único atrativo que se justifica pelo seu posicionamento espacial e a baixa capacidade de suporte dos campos de altitude.

Tabela 3 - Distribuição dos atrativos turísticos em relação às unidades de paisagem.

\begin{tabular}{|l|c|}
\hline \multicolumn{1}{|c|}{ Unidade de paisagem } & $\begin{array}{c}\text { Número de } \\
\text { Atrativos }\end{array}$ \\
\hline Vales da escarpa de falha & 7 \\
Vale do Bonfim & 4 \\
Planaltos Dissecados & 4 \\
Planalto da Pedra do Sino & 5 \\
Planalto do Açu & 1 \\
Escarpa de falha & 6 \\
\hline
\end{tabular}


OLIVEIRA, S.N. etal.
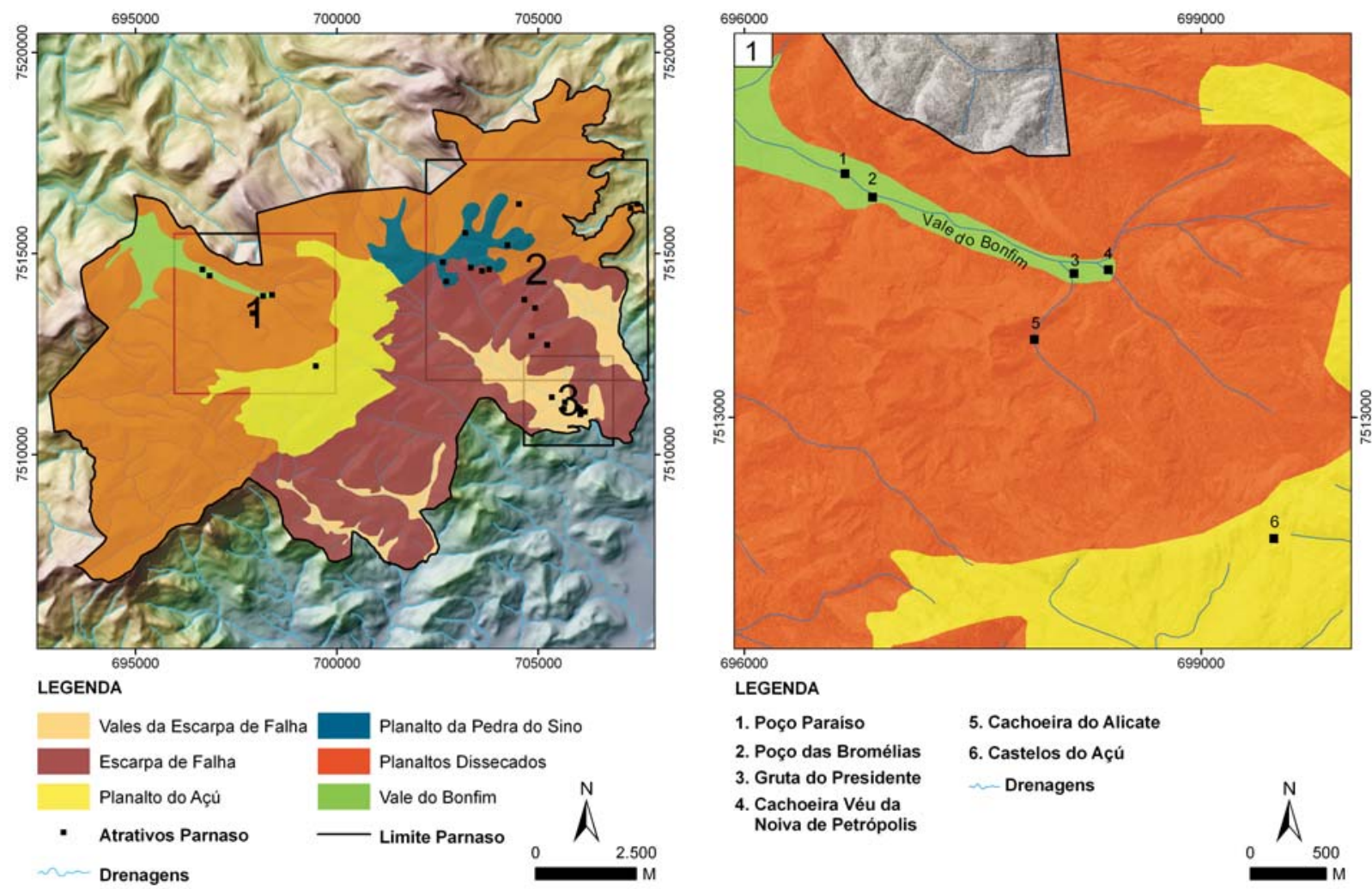

705000
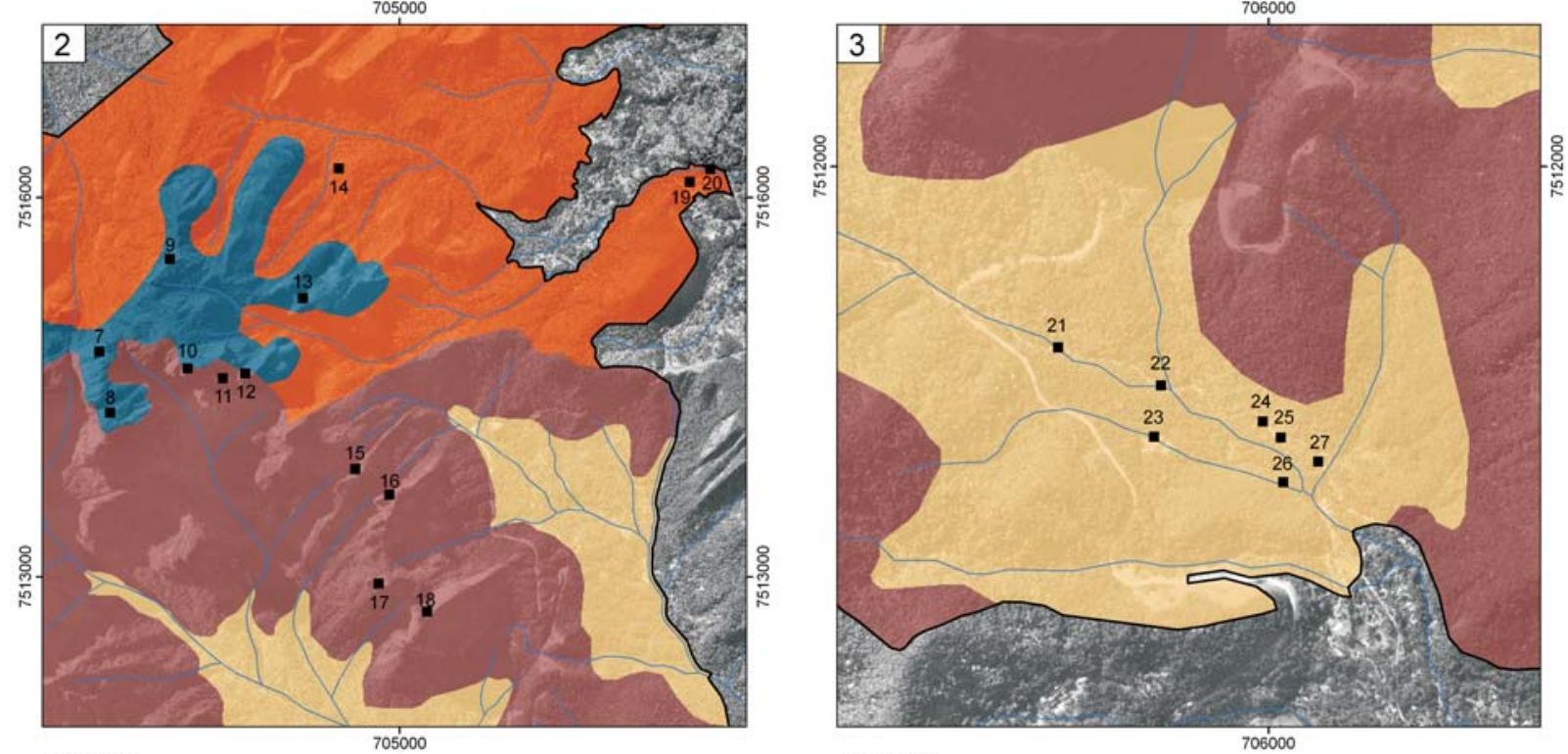

LEGENDA

LEGENDA

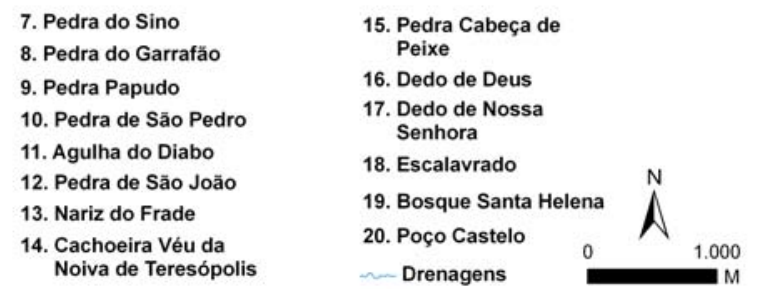

21. Poço Verde

22. Poço Preguiça

23. Museu Von Martius

24. Poço Ponte Velha
25. Poço Sossego

26. Ruinas de Guapimirim

27. Capela Nossa Senhora

da Conceiçăo do Soberbo

$\sim$ Drenagens

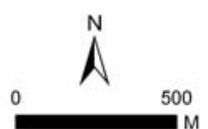

Figura 14 - Distribuição espacial dos atrativos para exploração turística presentes no PARNASO. 


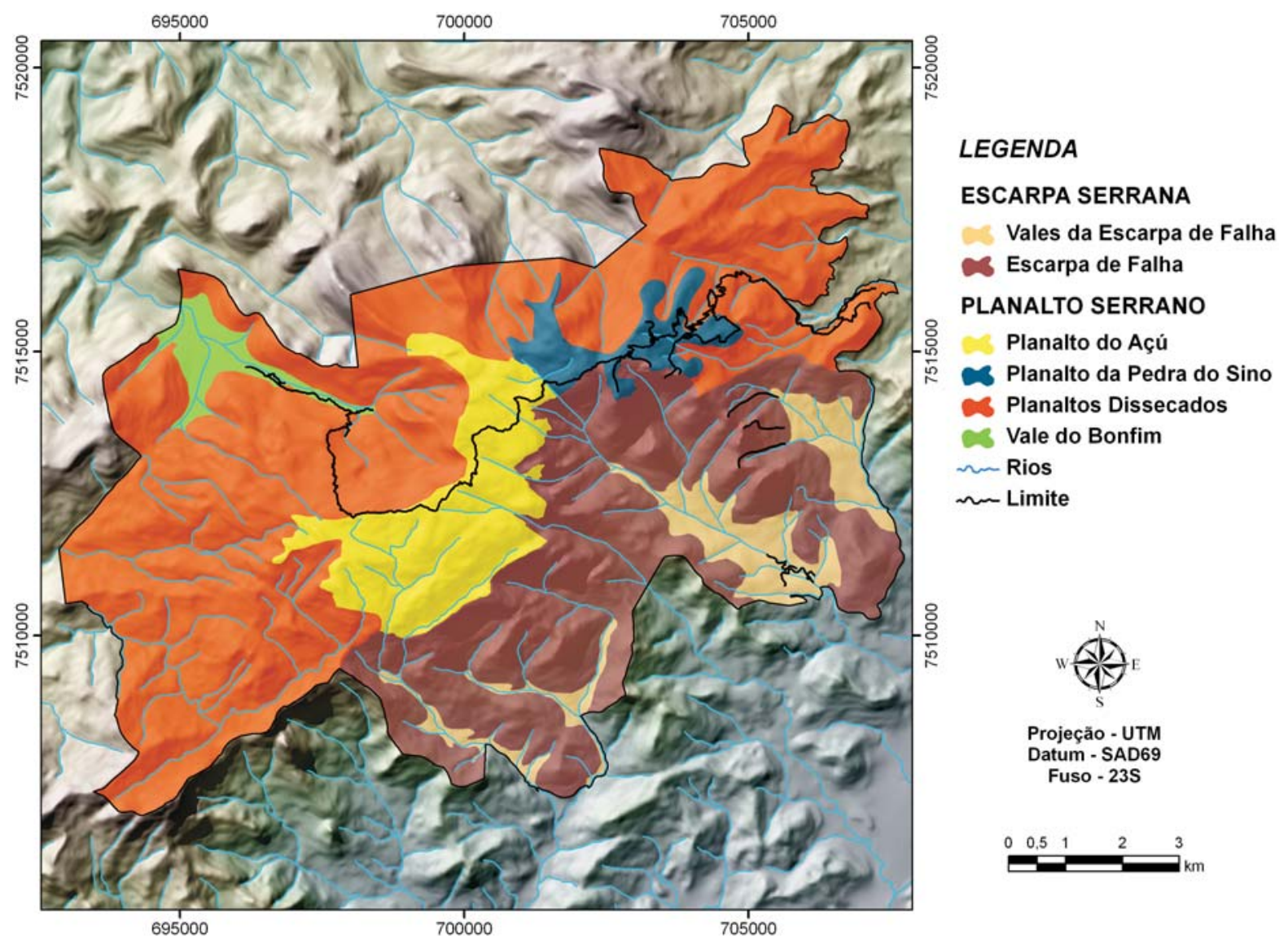

Figura 15 - Distribuição espacial das trilhas turísticas.

Complementarmente aos pontos turísticos, o parque apresenta trilhas turísticas que permite $o$ acesso e a visitação das diferentes unidades de paisagens (Figura 15). A principal trilha do parque é a travessia Petrópolis-Teresópolis com uma extensão de aproximadamente $30 \mathrm{~km}$. Essa trilha sendo uma das mais antigas do Brasil é considerada uma importante atividade de caminhada e montanhismo nacional, devido a sua dificuldade, beleza e história. Essa trilha consta no plano de manejo sendo permitida sua utilização, devendo ser devidamente acompanhado por guias turísticos. A travessia também possibilita o conhecimento de um grande número de atrativos do PARNASO (Poço Paraíso, Poço das Bromélias, Cachoeira do Véu da Noiva - Petrópolis, Gruta do Presidente, Cachoeira do Alicate, Castelos do Açu, Pedra do Sino, Cachoeira do Véu da Noiva - Teresópolis, Bosque Santa Helena e Poço Castelo). Além da travessia Petrópolis Teresópolis existe outras trilhas menores: Trilha Primavera, Trilha Mozart Catão, Trilha Suspensa, Travessia da Neblina e Caminho das Orquídeas. Desta forma, todas as unidades podem ser visitadas.

\section{Conclusões}

O ecoturismo permite integrar o desenvolvimento sócio-ecônomico e a preservação do meio ambiente, promovendo um novo tipo de consumo da paisagem. Neste propósito, o mapeamento e a compreensão da dinâmica evolutiva das diferentes paisagens permite um melhor aproveitamento dos seus recursos. Para tanto, deve-se compreender as unidades de paisagem, suas limitações físicas existentes e os mecanismos para a sua utilização, conjugando o seu uso às suas necessidades e demandas. A partir desse conhecimento podese projetar cenários futuros buscando uma racionalização adequada dessa unidades, que permita a sua exploração e também a sua conservação.

No presente trabalho foram utilizadas técnicas de sensoriamento remoto e análise de atributos de terreno para mapear as unidades de paisagem. No PARNASO foram identificados duas unidades na escala de regiões naturais e sete na escala de geossistema.

Desta forma, constata-se que a identificação de unidades de paisagem é importante para lenvatar a diversidade dos 
atrativos turísticos e para o planejamento do turismo e visitação do PARNASO. As atividades turísticas apresentam-se adequadas do ponto de vista da representatividade dos ambientes paisagísticos. A área destinada ao ecoturista consiste em uma pequena porção sendo a maior parte do parque destinada para conservação o que é adequado devido à fragilidade ambiental.

\section{Agradecimentos}

Os autores agradecem aos seguintes financiadores: CAPES pelo financiamento da bolsa de mestrado do autor Sandro Nunes de Oliveira; ao CNPq pelo financiamento das bolsas de pesquisa aos autores Osmar Abílio de Carvalho Júnior e Renato Fontes Guimarães, ao MMA que custeou o trabalho de campo e ao Parque Nacional da Serra dos Órgãos que forneceu importante apoio logístico. Em especial os autores agradecem a equipe do PREVFOGO do PARNASO que apoiou o trabalho de campo ajudando no aporte logístico de locomoção e mapeamento da área. Além disso, os autores agradecem aos membros do Laboratório de Sistemas de Informações Espaciais (LSIE) da UnB pelas críticas e sugestões realizadas durante a elaboração do artigo.

\section{Referência bibliográfica}

Abrams M. (2000) The Advanced Spaceborne Thermal Emission and Reflection Radiometer (ASTER): data products for the high spatial resolution imager on NASA's Terra platform. International Journal of Remote Sensing, 21 (5): 847-859.

Alonso, M.T.A. (1977) Vegetação. In: Goldenberg, C. (Ed.). Geografia do Brasil: Região Sudeste. Rio de Janeiro: IBGE, 3: 91-118.

Asmus, H.E. \& Ferrari, A.L. (1978) Hipótese sobre a causa do tectonismo cenozóico na região sudeste do Brasil. In: Aspectos estruturais da margem continental leste e sudeste do Brasil. Rio de Janeiro: CENPES/ DINTEP, p. 75-88 (Série Projeto REMAC 4).

Barbosa, A.M. (2003) Subsídios para o planejamento em ecoturismo na região do Médio Rio Grande, Minas Gerais, utilizando geoprocessamento e sensoriamento remoto. 249 f. Dissertação (Mestrado em Sensoriamento Remoto), INPE10293-TDI/912, 2003 - Instituto Nacional de Pesquisas Espaciais, São José dos Campos.

Barbosa, A.M.; Soares, J.V. \& Medeiros, J.S. (2003) Utilização de Sistemas de Informações Geográficas e produtos de sensoriamento remoto como subsídio para planejamento em ecoturismo no município de Capitólio - MG. In: Simpósio Brasileiro de
Sensoriamento Remoto, 11., Belo Horizonte. Anais do XI SBSR. São José dos Campos: INPE. p. 551558.

Bertrand, G. (1968) Paysage et Geographie Physique Globale Esquisse méthodologique. Révue Geographique des pyrinées et Du Sud-Ouest, Toulose, 39 (3): 249272.

Bertrand, G. (1978) Le paysage entre la nature et al société. Geographie Physique Global. Révue Geographique des pyrinées et du Sud-Ouest, Toulose, 49 (2): 16-26.

Bolós, M.C. (1981) Problemática actual de los estudios de paisaje integrado. Revista de Geografía, Barcelona, 15 (1-2): 45-68.

Brabyn, L. (1996) Landscape classification using GIS and national digital databasis. Landscape Research, 21:277-300.

Carvalho Júnior, O.A. \& Meneses, P.R. (2000) Spectral Correlation Mapper (SCM): an improvement on the Spectral Angle Mapper (SAM). In: Annual JPL Airborne Earth Science Workshop, 9., Pasadena, CA. Proceedings, JPL Publ. 00-18, 65-74.

Conti, J.B. (2003) Ecoturismo: paisagem e geografia. In: Rodrigues, A.B. (Org.). Ecoturismo no Brasil: possibilidades e limites. São Paulo: Contexto. p. 59-69.

Crepani, E.; Medeiros, J.S.; Hernandez Filho, P.; Florenzano, T.G.; Duarte, V. \& Barbosa, C.C.F. (2001) Sensoriamento Remoto e Geoprocessamento Aplicados ao Zoneamento Ecológico-Econômico e ao Ordenamento Territorial. INPE-8454-RPQ722, 2001. São José dos Campos: INPE. 124p.

Dantas, M.E. (2000) Mapeamento geomorfológico do Estado do Rio de Janeiro. Brasília: CPRM. Escala: 1:250.000. CD-ROM.

Departamento de Recursos Minerais - DRM. (2005) Projeto Caminhos Geológicos. Rio de Janeiro: Departamento de recursos Minerais do Estado do Rio de Janeiro (disponível em www.drm.rj.gov.br).

Ellenberg, H. (1979) Man's influence on tropical mountain ecosystems in South America. Journal of Ecology, 67: 401-416.

ESRI. (1998) Understanding GIS: the ArcInfo method. Redlands, CA: ESRI Press. 680 p.

Fabos, J.G. (1979) Planning and landscape evaluation. Landscape Research, 4 (2): 4-10. 
Ferrari, A.L.; Melo, E.F.; Vaz, M.A.; Dalcomo.; M.T.; Brenner, T.L.; Silva, V.P. \& Nassar, W.N. (1981) Folha Itaboraí, Maricá, Saquarema, e Baía de Guanabara. Projeto Carta Geológica do Estado do Rio de Janeiro. Rio de Janeiro: DRM/Geomitec.

Fujisada, H., Sakuma, F.; Ono, A. \& Kudoh, M. (1998) Design and preflight performance of ASTER instrument protoflight model. IEEE Transactions on Geoscience and Remote Sensing, 36 (4): 1152-1160.

Guerra, A.J.T. \& Marçal, M.S. (2006) Geomorfologia Ambiental. Rio de Janeiro: Bertrand Brasil. 192p.

Gyle, W.F. (1961) Morphometric analysis and the world-wide occurrence of stepped erosion surfaces. Journal of Geology, 69: 388-416.

Hermuche, P. M.; Andrade, A. C.; Guimarães, R.F.; Leal, L.R.; Carvalho Junior., O.A. \& Martins, E.S. (2003) Compartimentação geomorfológica em escala regional da bacia do rio Paranã. Revista do Departamento de Geografia (GeoUERJ), 372-381.

Hermuche, P.M.; Guimarães, R.F.; Carvalho, A.P.F.; Martins, E.S.; Fucks, S.D.; Carvalho Júnior, O.A.; Santos, N.B.F. \& Reatto, A. (2002) Morfometria como suporte para elaboração de Mapas Pedológicos: I. Bacias Hidrográficas Assimétricas. Documentos Embrapa Cerrados, 68: 1-18.

Hoersch, B.; Braun, G. \& Schmidt, U. (2002) Relation between landform and vegetation in alpine regions of Wallis, Switzerland. A multiscale remote sensing and GIS approach. Computers, Environment and Urban Systems, 26: 113-139.

Horton, R.E. (1945) Erosinal development of streams and their drainage basins: hidrophysical approach to quantitative morphology. Bulletin of the Geological Society of America, 56: 275-370.

Hutchinson, M.F. (1989) A new procedure for gridding elevation and stream line data with automatic removal of spurious pits. Journal of Hydrology, 106: 211-232.

Instituto Brasileiro de Desenvolvimento Florestal - IBDF. (1980) Plano de manejo: Parque Nacional da Serra dos Órgãos. Brasília: IBDF. 9p.

Instituto Chico Mendes de Conservação da Biodiversidade ICMBio. (2007) Plano de Manejo do Parque Nacional da Serra dos Órgãos. Brasília: Instituto Chico Mendes de Conservação da Biodiversidade. $365 \mathrm{p}$.

Leal, L.R.; Andrade, A.C.; Carvalho. Jr., O.A.; Guimarães, R.F.; Panquestor, E.K. \& Ramos, V.M. (2003) Definição de Unidades Geomorfológicas a partir de Imagens de Dados Morfométricos na Bacia do Rio Grande (BA). In: Simpósio Brasileiro de Sensoriamento Remoto, 11., 2003, Belo Horizonte. Anais do XI SBSR. São José dos Campos: INPE. p. 2055-2062.

Martinelli, G. (1989) Campos de altitude. Rio de Janeiro: Editora Index. $158 \mathrm{p}$.

Martins E.S.; Reatto, A.; Carvalho Júnior, O.A. \& Guimarães, R.F. (2002) Ecologia de Paisagem: conceitos e aplicações potenciais no Brasil. Série Documentos EMBRAPA-Cerrados, 121: 1-35.

Melton, M.A. (1958) Correlation structure of morphometric properties of drainage systems and their controlling agents. Journal of Geology, 66: 442-460.

Metzger J.P. (2001) O que é ecologia de paisagens? Biota Neotropica, 1(1): 1-9. http:// www.biotaneotropica.org.br/v1n $12 / \mathrm{pt} /$ abstract?thematic-review+BN00701122001

Moesch, M. (2000) A Produção do Saber Turístico. São Paulo: Contexto. 135p.

Moore, I. D.; Grayson, R.B. \& Ladson, A.R. (1991) Digital terrain modelling: a review of hydrological, geomorphological and biological applications. Hydrological Processes, 5: 3-30.

Moura, A.C.M.; Oliveira, S.P. \& Leão, C. (2006) Cartografia e geoprocessamento aplicados aos estudos em turismo. Geomática, Santa Maria, 1(1):77-87.

Nimer, E. (1977) Clima. In: Goldenberg, C. (Ed.). Geografia do Brasil: Região Sudeste. Rio de Janeiro: IBGE, 3: 51-89.

Nunes, B.A.; Ribeiro, M.I.C.; Almeida, V.J. \& Natali Filho, T. (1994) Manual Técnico de Geomorfologia. Rio de Janeiro: IBGE - Departamento de Recursos Naturais e Estudos Ambientais. 112p.

Oliveira, B.M.L.; Ramos, V.M.; Carvalho Júnior., O.A.; Guimarães, R.F.; Bettiol, G.M.; Gomes, R.A.T.; Martins, E.S. \& Reatto, A. (2005) Avaliação do uso da morfometria como suporte para a elaboração de mapa pedológico na bacia do Ribeirão da Pedreira - DF. In: Simpósio Brasileiro de Sensoriamento Remoto, 12., 2005, Goiânia. Anais do XII SBSR. São José dos Campos: INPE. p. 3167-3174.

Panquestor, E.K.; Leal, L.R.; Ramos, V.M.; Carvalho Júnior., O.A.; Guimarães, R.F.; Martins, E.S. \& Reatto, A. (2002) Uso de parâmetros morfométricos e dados estatísticos na definição e análise das Unidades de Paisagem da Bacia do Rio Corrente - BA. 
Boletim de Pesquisa e Desenvolvimento Embrapa - Cerrados, 65: 1-33.

Penha, H.; Ferrari, A.L.; Junho, M.C.B.; Souza, S.L.A. \& Brenner, T.L. (1981) Folha Itaipava. Projeto Carta Geológica do Estado do Rio de Janeiro. Rio de Janeiro: DRM/UFRJ.

Penha, H.; Ferrari, A.L.; Ribeiro, A.; Amador, E.S.; Pentagna, F.V; Junho, M.C.B. \& Brenner, T.L. (1979) Folha Petrópolis. Projeto Carta Geológica do Estado do Rio de Janeiro. Rio de Janeiro: DRM/UFRJ.

Pinto, C.P.; Serpa, J.C.; Dutra, J.E.B; Hettich, M. \& Andrade, N.T. (1980) Folhas Anta, Duas Barras, Teresópolis e Nova Friburgo. Projeto carta geológica do Estado do Rio de Janeiro. Rio de Janeiro: DRM/ Geosol.

Politano, W. (1994) Manual do emprego de imagens aéreas na avaliação do terreno. Jaboticabal: FUNEP. 33 p.

Rocha, L.G.M. (2002) Os parques nacionais do Brasil e a questão fundiária: o caso do Parque Nacional da Serra dos Órgãos. 190 f. Dissertação (Mestrado em Ciência Ambiental) - Universidade Federal Fluminense.

Ross, J. (1990) Geomorfologia ambiente e planejamento. São Paulo: Contexto. 85p.

Sarmiento, G. (1986) Ecological features of climate in high tropical mountains. In: F. Vuilleumier\& M. Monasterio (Ed.). High altitude tropical biogeography. Oxford University Press. p. 11-45.

Schmidt, J. \& Dikau, R. (1998) Extracting geomorphometric attributes and objects from digital elevation models - semantics, methods, future needs. In: R. Dikau \& H. Saurer (Eds.). GIS for Earth Surface Systems Analysis and Modelling of the Natural Environment. Schweizbart'sche Verlagsbuchhandlung. p. 153-173.

Schumm, S.A. (1956) Evolution of drainage systems and slopes in badlands at Perth Amboy, New Jersey. The Geological Society of America Bulletin, 67: 597-646.

Serrano L, Ustin Sl, Roberts Da, Gamon Ja \& Peñuelas J. (2000) Deriving Water Content of Chaparral Vegetation from AVIRIS Data. Remote Sensing of Environment, 74:570-581.

Silva, T.M. (2002) A Estruturação Geomorfológica do Planalto Atlântico no Estado do Rio de Janeiro. 265 f. Tese (Doutorado em Geografia) -
Departamento de Geografia - IGEO/UFRJ, Rio de Janeiro.

Silva, T.M. (2003) A estruturação geomorfológica do Planalto Atlântico no Estado do Rio de Janeiro. In: Simpósio Brasileiro de Geografia Física Aplicada, 10., Rio de Janeiro. Anais do X SBGFA, Rio de Janeiro: UERJ. $11 \mathrm{p}$.

Sistema Nacional de Unidades de Conservação - SNUC. (2000) Lei $n^{\circ}$. 9.985 de 18 de julho de 2000. Disponível em: <http://www.mma.gov.br>. Acesso em 21 jan. 2007.

Skilenar, P. \& Laegaard S. (2003) Rain-shadow in the high Andes of Ecuador evidenced by paramo vegetation. Arctic, Antarctic, and Alpine Research, 35: 8-17.

Sotchava, V.B. (1977) O estudo de geossistemas. Métodos em Questão, (16): 1-52.

Strahler, A.N. (1952) Hypsometric (area-altitude) analysis and erosional topography. Bulletin of the Geological Society of America, 63 (10): 1117-1142.

Thome, K.; Arai, K.; Hook, S., Kieffer, H.; Lang, H.; Matsunaga, T.; Ono. A.; Palluconi, F.; Sakuma, H.; Slater, P.; Takashima, T.; Tonooka, H.; Tsuchida, S.; Welch, R.M. \& Zalewski, E. (1998) ASTER preflight and insight calibration and the validation of level 2 products. IEEE Transactions on Geoscience and Remote Sensing, 36(4): 1161-1172.

Tricart, J.J.L. (1965) Principes et méthodes de la geomorphologie. Paris: Masson et Cie. Editeurs. $460 \mathrm{p}$.

Tricart, J.J.L. (1977) Ecodinâmica. Rio de Janeiro: IBGE/ SUPREN. 91p.

Tricart, J.J.L. (1979) Paysage et écologie. Revue de Géomorphologie dynamique: géodynamique externe. Études intégrée du milieu naturel, XXVIII, 3:81-95.

Troll, C. (1966) Landscape ecology. ITC-UNESCO Centre for Integrated Surveys, Paper S. 4, 23 p

Troll, C. (1971) Landscape ecology (geo-ecology) and biogeocenology: a terminological study. Geoforum, 8: 43-46.

Ustin, S.L.; Roberts, D.A.; Gamon, J.A.; Asner, G.P. \& Green, R.O. (2004) Using imaging spectroscopy to study ecosystem processes and properties. BioScience, $54(6): 523-534$. 
Identificação de unidades de paisagem e sua implicação para o ecoturismo do PARNASO

Veldkamp, A.; Kok, K.; Koning, G.H.J.; Schoorl, J.M.; Sonneveld, M.P.W. \& Verburg, P.H. (2001) Multiscale approaches in agronomic research at landscape level. Soil \& Tillage Res., 58: 129-140.

Yamaguchi, Y.; Kahle, A.B.; Tsu H.; Kawakami T. \& Pniel M. (1998) Overview of Advanced Spaceborne Thermal Emission and Reflection Radiometer (ASTER).
IEEE Transactions on Geoscience and Remote Sensing, 36(4): 1062-1071.

Zimmermann, N.E. \& Kienast F. (1999) Predictive mapping alpine grasslands in Switzerland: species versus community approach. Journal of Vegetation Science, 10: 469-482. 